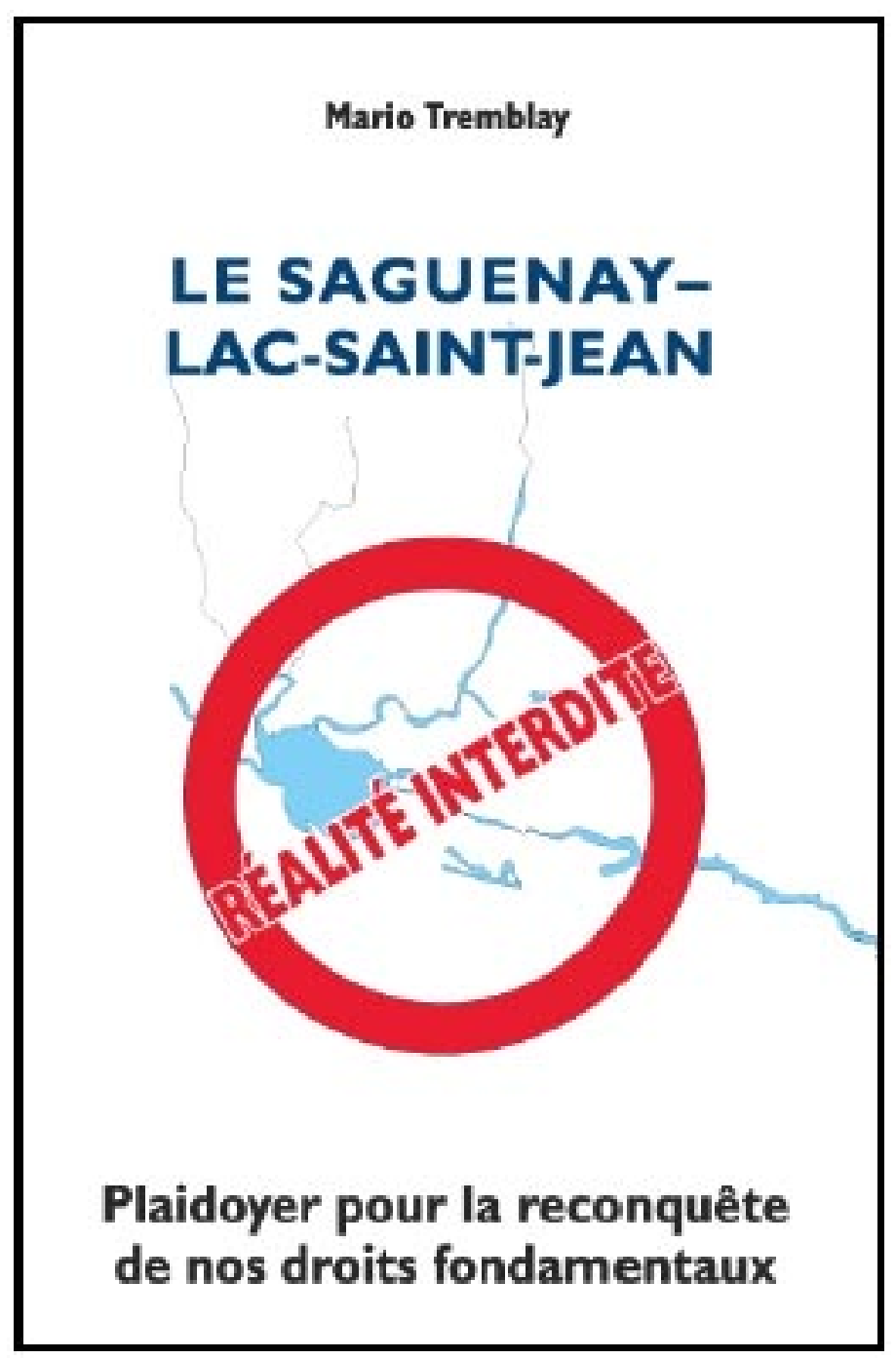




\title{
Mario Tremblay
}

\section{LE SAGUENAY-LAC-SAINT-JEAN ${ }^{\circ}$ 'R ALIT INTERDITE'}

\section{Plaidoyer pour la reconquête de nos droits fondamentaux}

\author{
Édition numérique adaptée pour \\ Les Classiques des sciences sociales \\ http://www.uqac.uquebec.ca/zone30/Classiques_des_sci \\ ences_sociales/index.html
}

Chicoutimi, 2003.

Publication à compte d'auteur. 


\title{
Le Saguenay-Lac-Saint-Jean réalité interdite
}

\section{Plaidoyer pour la reconquête de nos droits fondamentaux}

\author{
Auteur : \\ Mario Tremblay \\ de La Société du 14 juillet
}

Tous droits réservés. Toute reproduction, en tout ou en partie de cet ouvrage par quelque procédé que ce soit, y compris par photocopie, est interdite sans l'autorisation écrite de l'auteur.

Dépôt légal : $\quad 1^{\text {er }}$ trimestre 2003

Bibliothèque Nationale du Québec

Bibliothèque Nationale du Canada

ISBN 2-9807812-0-7 
Mario Tremblay, Le Saguenay-Lac-Saint-Jean. Réalité interdite.

Aux canadiens-français qui, tels des orphelins de leurs institutions démocratiques persistent quand même à bâtir pays! 


\section{Table des matières}

\section{Préface}

Avant-propos

Introduction

Chapitre I : L'inégalité des chances comme fondement du modèle québécois

Chapitre II : L'identité fondamentale des peuples autochtones du Canada

Chapitre III : La cession de nos droits et de notre territoire : trois objections de fond

Chapitre IV: La violation des droits fondamentaux des autochtones canadiens-français : contexte et ampleur

Chapitre V: Des hypothèses, des choix et des violations synonymes de fermeture de régions

Des hypothèses économiques pour développer les régions

La réaction devant la connaissance des faits

Les droits des autochtones amérindiens

Chapitre VI : L'équité n'est pas l'égalité

Collectivement, vivre dignement ou disparaître

$\underline{\text { Prendre action }}$

Conclusion : Notre devoir de dignité 
Mario Tremblay, Le Saguenay-Lac-Saint-Jean. Réalité interdite.

\section{Références bibliographiques}

Lexique

Remerciements

Annexe 1: Extraits pertinents de la Loi constitutionnelle de 1982 


\section{Préface}

Cet ouvrage de Mario Tremblay traite de la loi constitutionnelle du Canada vue par un simple citoyen. À la lecture, on constatera que l'ouvrage peut être apprécié d'au moins trois façons, selon que l'on se sent simple citoyen canadien sans plus, citoyen canadien du Québec, ou enfin citoyen canadien du Québec mais résidant dans une quelconque région dite «ressource », et notamment au Saguenay-Lac-Saint-Jean ou sur la Côte-Nord.

- Dans le premier cas, le texte revêt un caractère formatif offrant, en contexte, au lecteur curieux - sans être ni expert, ni impliqué politiquement - un condensé de jurisprudence touchant l'exercice de la loi, combiné avec les intentions, l'esprit et les valeurs qui animèrent ceux à qui on doit la première loi du pays.

- Dans la deuxième éventualité, le texte revêt un intérêt non seulement théorique, mais il fournit de surcroît une dénonciation en règle de politiques gouvernementales aux conséquences discriminatoires et inégalitaires qui contreviennent à l'esprit même et à la lettre de la loi constitutionnelle.

- Dans le troisième cas enfin, l'ouvrage a toutes les caractéristiques d'une arme de combat, à la disposition de tous ceux et de toutes celles qui, dans les faits, sont confrontés à ces politiques gouvernementales, qui en subissent les effets et qui sont ainsi contraints de défendre leurs intérêts fondamentaux par le truchement des droits qui leur sont reconnus dans la Constitution contre l'arbitraire de l'État et la pratique du pouvoir. 


\section{L'intérêt théorique}

De l'aveu de ses concepteurs, la Loi constitutionnelle canadienne fut imaginée à l'origine comme le recours suprême à la disposition des citoyens canadiens pour s'opposer à l'arbitraire de politiques imposées par l'État ${ }^{1}$, spécifiquement des politiques ayant pour effet de violer le principe de l'égalité des chances reconnu à tous et partant, de violer la liberté de certains en faveur de la liberté des autres. Or, pour servir à cette fonction, il fallait que le texte constitutionnel satisfasse à un certain nombre de conditions essentielles.

1. Il fallait que le texte de la loi soit compréhensible, écrit dans des mots clairs, univoques et accessibles à tout citoyen qui aurait éventuellement à l'utiliser pour les fins pour lesquelles la loi aura été conçue. Il fallait donc éviter que le texte de la loi ne soit accessible qu'aux seuls avocats, historiens et autres exégètes. En effet, comment logiquement une loi pourrait-elle servir à la protection des citoyens si ceux-ci ne peuvent eux-mêmes la comprendre et donc l'utiliser à bon escient?

2. Il fallait que les articles de la loi ne se contredisent pas mutuellement et ne puissent être interprétés dans un sens qui les ferait se contredire. Dans tel cas, la loi serait une passoire qui ne pourrait servir aux fins pour lesquelles elle aurait été promulguée.

3. Il fallait aussi que toutes les autres lois du pays - le Canada en l'occurrence - soient subordonnées à cette loi unique qui les encadre toutes sans exception. Ainsi, il fallait que la Loi consti-

Pierre Elliott Trudeau « Des valeurs d'une société juste », dans Les années Trudeau, 1990, p. 379-407. 
tutionnelle ait primauté non seulement sur toutes les autres lois canadiennes mais aussi sur les lois provinciales.

4. Enfin, il fallait que l'exercice de la loi et la jurisprudence qui s'y rattache soient conformes à l'esprit de la loi, accessibles à travers la pensée de ses concepteurs. C'est ce qui établit la différence entre une règle de conduite conçue pour assurer l'obéissance aveugle des citoyens et une autre règle de conduite constituant le moyen indispensable pour satisfaire à des valeurs premières dans notre société et auxquelles les citoyens peuvent adhérer librement, volontairement et consciemment. Telle est, selon moi, l'une des contributions principales de l'ouvrage de Mario Tremblay qui met en lumière cet aspect fondamental de la Loi constitutionnelle du Canada.

Ainsi, on apprend qu'aux termes de la constitution de notre pays, seuls les citoyens ont des droits alors que les droits dont disposent les collectivités - celles du Québec par exemple - sont en fait des droits délégués par $C H A C U N$ des citoyens à des organismes publics qui en sont les fiduciaires.

On apprend aussi que, selon les concepteurs de notre constitution, cette manière de faire permet d'éviter que dans l'exercice de leur propre liberté, les plus puissants, les plus forts, les plus riches, les plus savants, les plus intelligents n'entravent la liberté des autres citoyens du pays, ou même la subordonnent à la leur. Mais plus encore, selon l'esprit de ses concepteurs, la Loi constitutionnelle et surtout la Charte canadienne des droits et libertés qui en constitue la première partie, permettent même de prévenir que les majorités briment les droits des minorités et vice versa (Trudeau op. cit. p. 387).

En effet, la valeur de l'égalité des chances pour tous, sans discrimination d'aucune sorte incarnée dans le droit, constitue l'outil de 
prévention qui, en toute logique et en principe, empêche de porter atteinte à la liberté des autres, en permettant à tout citoyen de se défendre contre toute discrimination exercée contre lui. Dans ce contexte, l'acte constitutionnel est lui-même le moyen d'imposer à tous le respect du droit fondamental de tout citoyen canadien à l'égalité des chances.

\section{L'intérêt pratique}

Au-delà de l'intérêt théorique, le lecteur peut aussi s'interroger sur les motivations pratiques qui poussent un simple citoyen du Québec à publier sur la Loi constitutionnelle canadienne de 1982 . Qu'est-ce que cet écrit ajoute à ce que tant de juristes, d'experts et d'exégètes provenant de partout au Canada ont déjà publié sur la question?

Bien que Mario Tremblay ne soit ni juriste, ni expert, ni exégète, il est un citoyen canadien qui, à l'instar de plusieurs autres comme lui, a acquis la conviction que le gouvernement québécois exerce consciemment et délibérément depuis une trentaine d'années une politique fondamentalement discriminatoire envers certains citoyens du Québec. Cette politique discriminatoire fondée sur la région de résidence entrave systématiquement le développement de certaines régions à l'avantage d'autres, jusqu'à engendrer la désintégration politique, économique et sociale des communautés affectées, avec tous les préjudices que cette situation fait subir aux citoyens que ces communautés locales et régionales. Une telle situation contrevient à l'évidence à plusieurs dispositions de la Loi constitutionnelle de 1982, en particulier à celles qui traitent de l'égalité des chances dont est censé jouir tout citoyen canadien. D'ailleurs, les convictions développées en ce sens sont appuyées sur des faits extérieurs, identifiables, mesurés et mesurables, et non 
sur de simples impressions. Des faits existent qui confirment que cette situation d'inégalité des chances et de discrimination envers les citoyens sur la base de la région d'appartenance distingue fondamentalement et globalement le Québec des autres provinces canadiennes situées plus à l'ouest.

De surcroît, cette pratique discriminatoire vient de «s'enrichir» d'un nouveau paramètre : en effet, le gouvernement québécois vient de concéder à certains citoyens canadiens, mais pas aux autres, le privilège de posséder des terres en propre, d'y exploiter les richesses tout en retirant des redevances, d'y faire des lois, des constitutions, etc. Cette concession reconnaît même la supériorité des uns et l'infériorité des autres sur la base de la race et de l'origine ethnique. Ainsi le projet de traité de l'Approche commune, s'il était adopté, aurait pour effet de créer une jurisprudence par laquelle les gouvernements des autres provinces pourraient se voir tenus de céder des terres réclamées par les nations amérindiennes, incluant le droit de "dominer » les citoyens canadiens d'autres races déjà implantées sur ces mêmes terres. Une telle situation aurait pour effet de subordonner la citoyenneté canadienne à la citoyenneté amérindienne sur les territoires concédés par les autorités provinciales.

De plus, cette situation aurait pour effet de légaliser la discrimination entre les citoyens non seulement sur la base de la région d'appartenance, mais également sur la base de la race et de l'origine ethnique, faisant ainsi des premières nations du Canada, non pas seulement des nations premières selon l'histoire, mais aussi des nations faites d'individus premiers en droits et en privilèges: une situation qui contredirait à sa face même la validité de la Loi 
constitutionnelle et les valeurs d'égalité pour tous dont ses pères l'ont dotée et dont elle est porteuse ${ }^{2}$.

\section{L'intérêt personnel}

Mais au-delà des intérêts théoriques et pratiques, le texte de Mario Tremblay rejoint dans les faits les intérêts non pas seulement collectifs, mais d'abord personnels et fondamentaux de très nombreux canadiens: les intérêts vitaux et personnels des autres citoyens qui, comme lui, habitent dans une de ces régions soumises depuis trois décennies à l'arbitraire de politiques économiques et sociales inégalitaires, systématiquement appliquées par l'État québécois, et qui de surcroît seraient éventuellement soumises aux dispositions prévues dans le traité de l'Approche commune. Ces citoyens - que l'histoire, la naissance et les aléas de la vie ont placés dans une situation discriminatoire - doivent, à moins de fuir pour aller vivre ailleurs, envisager de se battre pour échapper aux conséquences des inégalités auxquelles on les a soumis à leur insu. Ils n'ont plus d'autres armes à leur disposition pour ce faire, que cette loi qui leur fut léguée par les pères du Canada moderne. Cette loi fut faite pour tous les Mario Tremblay du Canada, quelque soit leur nom. Elle fut faite pour chacun de ceux qui auraient à affronter semblable situation que celle à laquelle sont confrontés tous les citoyens canadiens qui habitent au Saguenay-Lac-St-Jean.

2 La constitution ayant été faite pour des citoyens vivants et des personnes humaines - et non pour des nations premières et des nations secondes - on remarquera que les ancêtres décédés ne peuvent négocier pour leurs descendants vivants des droits supérieurs à ceux des autres vivants du pays. 
Des questions en quête de réponse

Le texte de Mario Tremblay suscite cependant certaines questions auxquelles il reste encore à répondre, dont celles-ci en particulier. Depuis que la violence et la guerre ne sont plus des options, il ne reste au citoyen que le recours à la loi pour défendre ses droits. Dans un pays démocratique comme le Canada, dans quelle mesure le citoyen ne serait-il pas l'un des principaux, sinon le premier agent responsable des malheurs sociaux et économiques qui affligent sa communauté ? En effet, en négligeant et même en refusant de se prévaloir des droits qui lui sont conférés par la loi constitutionnelle, ne se trouverait-il pas à abdiquer la souveraineté qu'il a reçue en héritage, en faveur d'institutions qu'il devrait en principe pouvoir contrôler? Dès lors, qu'advient-il dans le cas où ces mêmes institutions brimeraient la liberté ou réduiraient l'égalité des chances d'un quelconque citoyen canadien, incluant lui-même? Mario Tremblay, pour sa part, a su se trouver des réponses à ces questions.

Mais, au Québec, il resterait encore à faire la preuve que la Loi constitutionnelle de 1982 est bien cette arme imaginée par ses concepteurs. Une arme qui, entre les mains de citoyens canadiens justifiés de le faire, devait permettre à ces mêmes citoyens de se protéger contre l'arbitraire de l'État.

Charles Côté

Décembre 2002 


\title{
Avant-propos
}

\section{$\underline{\text { Retour à la table des matières }}$}

\begin{abstract}
u Saguenay-Lac-Saint-Jean et sur la Côte-Nord, des hommes A et des femmes vinrent s'établir. Dans un esprit de liberté, d'égalité et de partage, par l'entraide, la collaboration et la division du travail, les bâtisseurs de Pays aspiraient à se réaliser pleinement. Ils déléguèrent au gouvernement la tâche de favoriser leurs intérêts collectifs afin que jamais leur dur labeur ne soit réduit à néant. Ces hommes et ces femmes, nos aïeux, firent une grave erreur.
\end{abstract}

Contre toute attente, à partir de 1970, hypocritement, sans opposition des Assemblées de nos Élus, le gouvernement a cessé de favoriser également les intérêts de toutes les collectivités* régionales. Il avait imaginé et mis d'avant une politique* économique fondée sur la ségrégation* de la moitié des collectivités humaines du Québec. Par ses orientations, ses politiques et ses pratiques, il a cessé de respecter notre droit* fondamental à l'égalité sans discrimination. Entretenant à notre endroit un stéréotype*, celui de « région ressource», il nous assignait illégalement une place et un rôle prédéterminés, partiels et spécialisés dans la société québécoise. Les éléments jeunes de nos collectivités régionales « ressources » étaient ainsi voués à prendre une place et à occuper un rôle qui leur avait été secrètement et illégalement attribué. Tout était ainsi programmé pour qu'ils aillent, telle une armée de conscrits, renforcer le tissu social et économique d'une région vouée à survivre à toutes les autres, la grande région de Montréal.

* Les mots suivis d'un astérisque sont définis au Lexique. 
Contrairement au vœu de nos ancêtres et des citoyens* canadiens des autres provinces, on nous écartait ainsi d'une société où tous se voient reconnus par la loi, comme des êtres humains et des membres égaux, comme des citoyens tous aussi capables et méritant le même intérêt, le même respect et la même considération. En matière de développement économique, le gouvernement avait remplacé par ses hypothèses*, des principes et des règles universellement éprouvés. Alors qu'en 1982, de telles règles devenaient des valeurs et des droits garantis énoncés par la Constitution* canadienne, le gouvernement passait outre et violait impunément le contrat social fondamental institué. Jusqu'à l'année 2000, seule la grande région de Montréal se voyait gratifiée de l'application des droits fondamentaux qui pourtant appartenaient à l'ensemble. Bientôt, par l'Approche commune, se basant sur d'autres hypothèses, ce seront les Amérindiens innus, cette fois, qui à l'instar de la grande collectivité montréalaise, deviendront eux aussi privilégiés. Quant à nous, citoyens d'ici, nous sommes conviés à continuer à assister impuissants, au dépérissement de notre collectivité d'appartenance. Voilà comment au Québec, au nom d'un nationalisme basé sur l'exclusion sélective, sont sacrifiées des régions et des collectivités humaines.

Une société juste devait veiller à ce que tous les citoyens soient libres et égaux dans tous les domaines, où que ce soit au Québec. Elle devait veiller à ce qu'il ne soit exercé aucune discrimination basée, entre autres, sur le territoire d'appartenance et sur la race. Sa plus importante valeur ainsi que sa principale caractéristique se devaient d'être la liberté, l'égalité et leur réel exercice.

Pendant que collectivement, nous les bâtisseurs de pays sommes en voie de disparaître de nos régions, d'autres collectivités autochtones émergent, nous poussent à quitter notre terre et nous remplacent. Éclairées, elles réussiront là où nous avons collectivement échoué. Pour s'assurer de leur succès économique et social, leur 
exigence est simple. Elle est aussi lumineuse que désarmante : par l'Approche commune, un traité politique, les Innus s'assureront pleinement, sans compromis, que l'Assemblée nationale regroupant nos députés et notre gouvernement, fassent à leur endroit, le contraire de ce qu'ils nous ont illégalement fait: le respect entier des droits fondamentaux à l'égalité des chances sans discrimination. 


\section{Introduction}

Te viens d'un lieu et d'un temps où la soumission devant l'injustice signifiait mourir un peu. Je viens d'un endroit et d'un passé où Représenter les citoyens devenait un devoir sacré et un privilège : à l'image de nos droits, il devait se mériter chaque jour. En ce temps, un serment ne s'oubliait pas, un chat s'appelait un chat, un incompétent s'appelait un incompétent et nous étions aptes à distinguer qui était la grande gueule et qui était le grand homme. Les droits fondamentaux n'étaient pas négociables, à plus forte raison s'ils appartenaient seulement au citoyen. À titre de membres d'une communauté, nous élisions un chef d'abord et un parti ensuite. Jamais, nous ne nous serions soumis. Jamais nous n'aurions toléré longtemps un représentant élu qui ne représente pas la substance du Pays que nous bâtissions sur l'intégrité, l'égalité, la liberté et la justice.

Mon pays intime faisait partie de ces millions d'autres où les bibles appartenaient seulement au domaine du spirituel. L'honneur avait une signification et une importance prépondérante. Notre soif de liberté dans l'égalité nous commandait de poser des jugements de citoyens. En cas d'insatisfaction, nous nous mettions en devoir d'agir respectueusement mais efficacement. Nous n'entretenions aucune peur de la réprobation venant des valets qui, pour le profit de leurs maîtres et pour préserver leurs privilèges personnels, tentaient d'entraver notre légitime marche. Bien avant que la souveraineté ne débarque dans le paysage et devienne fétiche, nous étions déjà souverains : fiers, dignes et maîtres de nos droits. 
Patiemment, j'ai mené à terme une vaste quête pour satisfaire mes interrogations touchant ma valeur de citoyen dans ma région. Cette quête conduisait à la connaissance de nos droits fondamentaux à l'égalité sans discrimination.

Détrompé, j'ai observé mes représentants élus au Parlement et le gouvernement de ma société. Je ne puis faire autrement qu'être en perte de confiance envers nos institutions* démocratiques. Je vois maintenant ce vers quoi se dirige ma région et ce en quoi elle m'échappe à jamais. Je comprends que nous devons nous libérer de la domination d'un ancien rêve qui, pour ma région, a entraîné déportation, dépossession et désolation. Je comprends la nécessité vitale de me réapproprier mon statut d'autochtone canadien français du Québec. En posant ce geste souverain, je reprends possession de mes droits, de ma personne, de ma pensée, de ma volonté et de mon avenir. Muni de mes droits fondamentaux, tels qu'inscrits dans la Constitution canadienne, je redeviens cent fois plus important que l'illusion souverainiste; je redeviens pleinement capable de devenir égal en tout point aux autres québécois et canadiens.

Ce plaidoyer* pour que la réalité reprenne ses droits aurait dû être adressé à mes représentants élus. J'ai plutôt déterminé de le dédier aux vrais maîtres du pays : les citoyens. En particulier, aux collectivités humaines laissées-pour-compte qui ont bâti les régions du Saguenay-Lac-Saint-Jean et de la Côte-Nord.

Après lecture des prochains paragraphes, le lecteur est convié à faire un choix fondamental et souverain qui se pose simplement : pour la survie de sa collectivité régionale, il devra décider s'il est prêt à emprunter une avenue de solution qui n'est pas d'un usage familier dans ce pays. Elle mène à la défense citoyenne de nos droits fondamentaux, individuels et collectifs. Ces droits sont reconnus et confirmés dans la Constitution canadienne de 1982 et dans la Charte* des droits et libertés qui en fait partie intégrante. De plus, 
en matière de développement économique pour toute région, nos droits constitutionnels pointent une direction inverse à celle qu'a empruntée, depuis trente années, le gouvernement de la société québécoise.

Parmi ces droits, j'identifie plus spécifiquement :

- le droit fondamental à l'égalité garantie sans discrimination fondée, entre autres, sur des motifs tels la race et la région d'appartenance;

- le droit fondamental à l'égalité des chances économiques entre les collectivités régionales;

- le droit d'exiger que, devant le tribunal, l'Assemblée nationale de nos députés et le gouvernement, aillent justifier le bien-fondé en droit de deux intolérables discriminations. La première a trait à la discrimination économique dont font l'objet la région du Saguenay-Lac-Saint-Jean et les autres «régions ressources 》 (sic), utilisées au profit de la croissance économique de la grande région de Montréal. La seconde touche la récidive de la première mais, cette fois, au profit exclusif des Amérindiens de la région du Saguenay-Lac-Saint-Jean et de la Côte-Nord.

Le citoyen est artisan d'une double destinée, la sienne mais aussi celle de sa collectivité d'appartenance. S'il est prêt à poser les gestes démocratiques nécessaires pour que son propre pays cesse de l'exclure, la lecture de cet appel citoyen pour la reconquête de nos droits fondamentaux lui serait bénéfique. Il aurait des outils solides pour contribuer à le sauver. Ce Pays, peu importe qu'il l'identifie comme étant sa région, sa province, le Canada ou le continent. Son cœur est libre. Il est cependant certain que les générations futures seront redevables de son action citoyenne de bâtisseur.

Il se pourrait par contre qu'il ne se sente pas impliqué ou qu'il choisisse de ne pas adhérer aux valeurs, principes et droits éprou- 
vés précédemment énoncés. Devant la chronique de notre mort collective que je constate annoncée, incapable de réprimer mon désespoir, je lui livre ainsi le fond de ma pensée : "Abolis-toi mon ami! Entraîne avec toi le Pays que tes aïeux avaient bâti pour toi! Gave-toi de l'illusion des discours partisans! Continue à te laisser traiter en inférieur par ton gouvernement. Continue d'accueillir béatement les "raffinés " qu'il met en place et qu'à l'occasion, paniqué, il t'envoie en vue de t'infléchir, te décourager ou t'aveugler, pour que, toujours, rien ne change en ta faveur. Continue, subis et malheureusement disparais! ”

Quant à celui qui a choisi de rester, j'ai trouvé nécessaire de partager avec lui les fruits de mon travail. À cette fin, je me suis appliqué à retrouver et à mettre au jour les droits, les principes, les règles et les arguments fondés qui nous seront nécessaires pour alimenter, devant le peuple et devant la justice, la défense de notre région. J'éprouve de la gêne à devoir le préciser mais, dans cette conquête de notre dignité* perdue, nos opposants ne sont ni Anglais ni Iraquiens. Ce sont ceux qui, par leurs agissements serviles et par leurs fausses solutions, précipitent la mort de notre collectivité et s'en repaissent. Ces valets politiques et ces mercenaires intellectuels se manifesteront à nouveau et lanceront à tout vent que mes constats ne sont pas accrédités car je ne suis pas des leurs. Nous savons trop bien maintenant à quelles auges mangent ces béni-oui-oui qui nous vomissent à la figure leurs conclusions pontifiantes coiffées de leurs titres ronflants. À ceux-là je réponds déjà: "Comme d'habitude, faites demi-cercle par derrière et attaquez! Considérez cependant, pour votre gouverne, que je suis redevenu un Canadien français et qu'à ce titre, avec les armes que me procure la loi fondamentale de ce pays, j'entends combattre pour moi-même, pour mes frères, pacifiquement, démocratiquement mais sans merci ». 
Sachez qu'à titre de citoyen canadien-français égal en droit, ma région d'appartenance redevient le Saguenay-Lac-Saint-Jean. Cette terre, bien avant moi, mes ancêtres l'avaient baptisée de leur sueur, de leurs efforts individuels, collectifs et persévérants. Ils l'avaient défrichée, aménagée et embellie. Ma condition de citoyen du Saguenay-Lac-Saint-Jean fait partie de mon identité et de ma personnalité. Aucune force politique partisane ne peut m'en dépouiller. Je ne me soumets pas sans réagir à cette obscure volonté gouvernementale de faire de moi, de mes enfants et de mon groupe d'appartenance, des transplants pour le Grand-Montréal (la grande région montréalaise). C'est ici que je suis né, que je vis, que j'espère et que j'entends mourir. Si je devais partir, ce serait par le fait de ma seule volonté éclairée et de mon libre choix. Le fondement et le centre de ma vie citoyenne consistent à me réaliser pleinement dans mon milieu d'appartenance et dans la dignité.

Pour moi-même mais aussi pour ma collectivité, je veux sincèrement que soient remis en fonction les mécanismes d'État nécessaires à la satisfaction de notre droit fondamental garanti à l'égalité des chances. L'Assemblée nationale de nos Élus et le gouvernement ne disposent d'aucun droit et d'aucun intérêt juste et légitime pour me traiter inégalement. Les politiques et les dispositifs d'application des lois ne peuvent avoir pour effet de m'appauvrir et d'empêcher que je me réalise pleinement et dignement. Ils ne peuvent aussi avoir pour effet de dégrader les chances de développement de ma région, ni d'y raréfier les conditions nécessaires pour que les gens $\mathrm{y}$ demeurent et $\mathrm{y}$ prospèrent aussi bien que dans d'autres régions.

L'heure vient pour chacun de nous, de réaffirmer la primauté de sa citoyenneté canadienne-française du Québec. Le temps est venu d'affirmer que les bâtisseurs de pays que nous sommes ont garanti, par la Constitution canadienne, des droits fondamentaux à chaque être humain habitant le Canada. Ces droits sont au-dessus de la 
créature qui, entre les mains d'une élite suffisante et cruelle est devenue une bête laide, hypocrite, malfaisante et brutale. Elle ose encore appeler souveraineté, la négation de ce que nous sommes.

Munis de nos droits fondamentaux - tel un coffre d'outils efficaces dont nous avions oublié l'existence - nous pourrons recommencer à nous défendre convenablement. Rassemblant les lambeaux de démocratie et de droits fondamentaux abandonnés par nos élus territoriaux et le gouvernement de notre société, nous ferons renaître le pays auquel nous avons pleinement droit. Cette fois, il sera inclusif pour « nous » tous!

Les pages qui suivent expliqueront d'abord comment notre région est confrontée à l'inégalité des chances. Dans un chapitre particulier, elles traiteront de la confusion qui s'est installée autour de l'identité fondamentale des peuples autochtones du Canada et de certaines conséquences d'avoir accordé un statut spécial à une classe de Canadiens, les Amérindiens. J'identifierai ensuite six objections fondamentales à la rétrocession de mes droits fondamentaux et du territoire de ma région telle que pratiquée par le gouvernement à l'endroit des «régions ressources» et telle que confirmée dans l'Approche commune. Les trois premières objections se situent dans l'axe juridique créé par la Constitution. Une quatrième fournit une connaissance plus approfondie de notre environnement citoyen en matière de droits constitutionnels. Les deux dernières tracent le portrait des agissements d'un gouvernement qui maintient une politique menant les régions vers leur fermeture et qui - sous le prétexte de soudainement respecter $\underline{u n}$ article de la Constitution du Canada - est en train de rétrocéder aux seuls Amérindiens nos droits fondamentaux. En illustrant la différence entre équité et égalité, je me suis ensuite appliqué à porter la réflexion sur des bases qui permettent d'éviter certains pièges. Aussi, en soutien à une vaste cause juridique en droit à l'égalité, j'ai dressé une liste des principaux éléments de la preuve que la région 
est en mesure de fournir à la plus haute Cour du pays ainsi que ses légitimes réclamations et réparations. Enfin, j’ai exprimé en quoi nous sommes en devoir de nous porter à la défense de notre région.

Mario Tremblay 


\title{
Chapitre I
}

\author{
L'inégalité des chances comme \\ fondement du modèle québécois
}

$\mathrm{D}$ ans le contexte du sous-développement relatif - et vérifiable des régions du Saguenay-Lac-Saint-Jean et de la Côte-Nord, la politique gouvernementale de génération d'inégalités entre régions et l'Approche commune mettent à l'ordre du jour un principe incontournable qui fait partie de la famille des droits fondamentaux constitutionnels des individus et des collectivités humaines. Nous le reconnaissons sous le vocable de l'égalité des chances. À ce titre, nous identifions l'égalité des chances économiques entre toutes les régions et l'égalité des chances sociales de tous les individus et de leurs groupes d'appartenance. Pour sa réalisation, ce principe commande que, sans distinctions, y compris celles liées à la qualité du sang et à la région d'appartenance, les collectivités doivent disposer des conditions et moyens leur donnant des chances égales de se développer librement. Légitimement, une loi ou une politique gouvernementale ne peut avoir pour effet de traiter différemment quelque groupe que ce soit dans la société. Elle ne peut le priver d'un avantage consenti aux autres, parce qu'il est considéré à certains égards comme étant dans une situation différente des autres. Malheureusement, il appert qu'au Québec il en va autrement.

Dans le contexte constitutionnel évoqué, trois collectivités sont impliquées. Les deux premières sont la collectivité privilégiée de la grande région de Montréal et aussi la collectivité amérindienne innue. Toutes deux disposent d'un allié tout-puissant, le gouver- 
nement. Pour le profit et la croissance du Grand-Montréal et bientôt pour le profit du «développement» des collectivités innues, le gouvernement s'est emparé illégalement du droit de vie ou de mort sur les collectivités de certaines régions dont les nôtres. La troisième, la collectivité canadienne-française ${ }^{3}$ d'ici, doit affronter, seule, un ennemi qui s'est révélé être à deux visages : le même gouvernement. Sous cet angle, les chances deviennent encore plus inégales : d'ailleurs, elles le sont depuis trente ans.

Les collectivités régionales canadiennes-françaises et innues, par comparaison à celles de la grande région de Montréal, sont nettement sous-développées. Nous et les Innus, sommes aux prises avec des maux sociaux comparables. Face au gouvernement toutefois, nos poids politiques respectifs enregistrent une différence marquée. Suite à l'Approche commune, notre collectivité continuera d'être discriminée. L'autre, l'amérindienne, cessera de l'être car il lui sera donné d'aller rejoindre le niveau de socio-économique de la grande région métropolitaine.

3 L'expression « canadien français » réfère à cette facette de notre citoyenneté qui implique le recours à une constitution, la Constitution canadienne, pour encadrer l'action des institutions et une charte, la Charte canadienne constitutionnelle des droits et libertés, pour protéger les droits individuels et collectifs. 


\section{La Constitution et les inégalités régionales}

La partie III de la Constitution édicte les règles et engagements fondamentaux touchant les inégalités régionales et la péréquation. L'article 36. (1) engage le Parlement et les législatures, ainsi que les gouvernements fédéral et provinciaux à "promouvoir l'égalité des chances de tous les Canadiens dans la recherche de leur bienêtre ", à "favoriser le développement économique pour réduire l'inégalité des chances» et à "fournir à tous les Canadiens, à un niveau de qualité acceptable, des services publics essentiels* $»(v$. Annexe I). Cette clause 36. (1) engage donc les gouvernements fédéral et provinciaux à promouvoir l'égalité des chances de tous les Canadiens par le truchement de leurs collectivités régionales, alors que la clause 36. (2) garantit le principe des paiements de péréquation destinés à redistribuer les revenus des provinces riches vers celles qui le sont moins. "Une fois enchâssé dans la Constitution, en 1982, le principe de l'égalité régionale acquit le statut de droit économique fondamental ... les régions devaient être au cœur de tous les programmes nationaux» (Axworthy, 1990).

Le terme région et régional utilisé dans la partie III de la Constitution renvoie à un territoire délimité possédant des caractéristiques particulières et une certaine unité. La Constitution ne prescrit pas une quelconque norme officielle ou légale quant à la dimension territoriale de la « région ». En effet, la Constitution s'applique indifféremment à tout citoyen là où ce dernier et son groupe d'appartenance habitent: village, ville, MRC, région économique, province ( $v$. Axworthy, 1990).

Mal informés quant à la loi fondamentale de ce pays, malgré eux, les citoyens canadiens-français d'ici sont maintenus dans un état de non application de leurs droits fondamentaux à l'égalité garantie sans discrimination. De plus, ils ne peuvent réellement compter sur aucun représentant élu qui soit suffisamment affranchi de son parti politique et en maîtrise suffisante des droits et règles édictés par la Constitution du pays. Devenus étrangers à ces fondements qui garantissent démocratie et développement, aucun d'eux ne 
démontre pouvoir s'acquitter valablement de son Serment au peuple du Québec* par la réalisation de ses fonctions de "contrôleur* de l'action gouvernementale » et d'intermédiaire qui «s'assure que sa communauté reçoive sa juste part des programmes publics» (Loi sur l'Assemblée nationale du Québec ) ${ }^{4}$.

De son côté, en marge de la société, la collectivité amérindienne persiste à se percevoir comme issue d'une race à part à tous points de vue. Elle est isolée, sous-développée et aux prises avec divers problèmes sociaux. Son triste état - qui, somme toute, ressemble à celui de la collectivité régionale canadienne-française voisine aujourd'hui, elle l'utilise adroitement. Avec le gouvernement, son complice, elle l'invoque pour infléchir et soumettre l'autre collectivité régionale, la nôtre. Ainsi, depuis peu et à la surprise générale, du capitalisme et des institutions démocratiques, les leaders amérindiens réclament le meilleur. Par contre, de la société civile voisine dont ils sont nécessairement tributaires, ils rejettent la solidarité et la fraternité. Avec le soutien du gouvernement du Québec, leurs chefs prônent l'ethnocentrisme*. Ne s'agit-il pas là d'une

4 Ainsi, le lecteur comprendra que la règle de la juste part des programmes publics repose sur la comparaison de l'ampleur ou du volume que reçoit, en financement des programmes publics et en emplois (en découlant), chacune des régions et des collectivités locales à l'intérieur desdites régions. Le critère incontournable pour déterminer si entre deux régions ladite part est juste, est fort simple. Il n'y a qu'à observer le taux d'emploi. Une part injuste en fonds publics crée les conditions du sous-développement. Ainsi, les jeunes d'une région dont la part est maintenue inférieure à une autre région, s'installeront dans l'autre région où la part a été maintenue (illégalement) supérieure, celle-ci offrant plus d'opportunités d'emplois comparativement à sa région d'origine. Pour juger de l'importance prépondérante des programmes publics, pensons aux sommes colossales et aux milliers d'emplois en éducation, en santé et services sociaux, en administration gouvernementale. Les dépenses publiques représentent la part majeure des entrées de devises dans les régions du Québec (Côté, 2001). 
propension néfaste du nationalisme indépendantiste à préconiser des états autodéterminés et fondés sur la race, la langue, la culture pour l'acquisition de compétences constitutionnelles et l'obtention des moyens nécessaires à la promotion de sociétés distinctes ? À terme, celles-ci deviennent rivales entre elles.

\section{Le mot nation}

« Le mot nation ou nationalité, du latin nasci (naître), désigne le plus souvent une communauté ethnique, ayant une langue et des coutumes communes. Mais il arrive aussi qu'à l'inverse, ce soit l'état, formé à l'origine de plusieurs communautés ethniques, qui donne naissance à une nation : le mot s'entend alors d'une société politique ayant un territoire et des intérêts depuis longtemps communs. Au Canada, il n'y a ou aura de nation canadienne qu'en autant que les communautés ethniques réussiront à exorciser leurs nationalismes respectifs » (Carr, 1946).

Dans ce contexte, la Constitution de 1867 a donné naissance à neuf autres provinces, toutes distinctes les une des autres en vertu de leurs frontières propres, de leurs composantes ethniques, de leurs lois et partant de leurs cultures. Contrairement aux Québécois, ni les autochtones amérindiens, ni les membres des minorités culturelles, ni les autres communautés ne constituent des collectivités définies par un territoire précis et jouissant de pouvoirs législatifs, exécutifs et judiciaires (c'est pourtant ce que s'apprête à reconnaître aux seuls Innus, l'Approche commune).

Par conséquent, ces collectivités en tant que telles ne reçoivent dans la Constitution aucune compétence constitutionnelle pour promouvoir leur société distincte. Les dispositions constitutionnelles relatives aux droits ancestraux des peuples autochtones et à la préservation du patrimoine multiculturel des Canadiens n'ont pour but et pour effet que de donner aux membres de ces collectivités 
une garantie judiciaire supplémentaire contre toute interprétation de la Charte canadienne où ils risqueraient d'être oubliés.

Pour mieux satisfaire à son nationalisme, la collectivité innue a en main ses propres cartes. La première réside dans l'article 35 de la loi constitutionnelle de 1982. Normalement, à la condition qu'elle satisfasse au moins à la règle de la preuve énoncée par la Cour suprême, elle pourrait se faire reconnaître un titre aborigène. Cette reconnaissance se formaliserait par un traité. Un tel traité, par son contenu, ouvrirait, pour elle seule, la voie à l'égalisation de ses chances pour son propre développement économique. Dans sa donne auprès du gouvernement, elle dispose aussi d'un second atout. Il s'agit du puissant lobby des Premières nations. C'est par ce dénominateur que fut affaiblie la signification profonde de la reconnaissance que leur accordait, en 1982, la Constitution canadienne. Par ce qualificatif de Première nation, on a sapé patiemment le caractère inclusif intrinsèque à l'article 35 , de toutes les collectivités autochtones du Canada. Utilisant la situation des autochtones amérindiens de l'Ouest du Canada, le puissant lobby des Premières nations a su étendre le caractère alarmant de la situation de ces derniers aux autres provinces, en particulier au Québec. En effet, en 1982, en adoptant l'article 35, le Parlement avait voulu prioritairement promouvoir des solutions à la cause spécifique, et décrite comme plus difficile, des Amérindiens de l'Ouest du Canada (Débats de la Chambre des Communes, 1982).

La solution à l'état de sous-développement des deux collectivités, l'amérindienne et la nôtre, passe par une application rigoureuse de la Constitution et de la Charte constitutionnelle. Il s'agit d'une solution inclusive donc, sans distinction liée à la race et à la région d'appartenance. Une telle solution d'ensemble repose sur 
l'application par le gouvernement, des articles premier, 15 et 36. (1) a) ${ }^{5}$. Ces principes et règles font de l'égalité des chances économiques et sociales entre les régions, un fondement constitutionnel incontournable et éprouvé. C'est une obligation née directement du contrat social fondamental entre tous les citoyens canadiens.

Dans ses pratiques, sauf quand il en va des intérêts de la grande collectivité montréalaise, le gouvernement détermine d'adhérer ou de ne pas adhérer à ces devoirs auxquels l'engage expressément la Constitution. Il procède à une application sélective (régionale) de la Constitution et de la Charte constitutionnelle des droits et libertés. Ses choix semblent dépendre de la force du rapport politique qu'entretiennent avec lui les collectivités - qui bien avisées, ne se sont pas encore laissées endormir par les discours partisans - et les groupes d'intérêts financiers internationaux et les autres lobbies. Pourtant, les droits à l'égalité ne constituent pas un privilège à reconnaître à certaines collectivités ou à des groupes ciblés par le gouvernement, selon son bon plaisir et au gré des menaces qui pèsent sur la collectivité qu'il privilégie. Ces droits ne sont pas un rêve; ils ne sont pas une conséquence reportée ou un effet futur découlant de l'indépendance nationale. $\mathrm{Au}$ contraire, ils sont, depuis 1982, une règle de base qui précède les balbutiements du rêve. Si chacune des régions ne jouit pas d'une application intégrale et sans discrimination de tels droits fondamentaux, rien n'est possible : pas plus le Canada uni que le Québec indépendant.

Un fait demeure cependant : le Canada est fondé sur des principes qui reconnaissent la primauté $d u$ droit. Il n'est pas fondé sur les

5 L'annexe I regroupe l'énoncé de tous les articles de la Loi constitutionnelle de 1982 cités dans cet ouvrage. 
interprétations auxquelles se livrent les groupes d'intérêts en collusion avec le gouvernement. Cette seule règle devrait avoir pour effet d'obliger ce dernier à contenir l'appétit vorace des Innus. Car, contrairement à la propagande gouvernementale, il est objectivement faux de prétendre que le niveau de développement de la population régionale est le même que celui du reste du Québec, encore moins quand on le compare à celui de la majorité résidant dans la grande région de Montréal.

Au mépris de la réalité observable et vérifiable, il serait donné, par traité, à la collectivité amérindienne des outils, des leviers, des droits et des certitudes constitutionnelles dont l'autre collectivité a absolument besoin, elle aussi, pour sa survie. En ne donnant pas aux Canadiens français d'ici, les mêmes outils et droits qu'il s'apprête à reconnaître aux Amérindiens, le gouvernement maintient et empire les conditions du sous-développement régional.

Avant l'Approche commune, par l'effet de sa politique régionale et surtout à partir de 1970, cette région a été laissée pour compte. Le gouvernement l'a injustement soumise à des hypothèses qui, sur les plans social et économique, la mettaient au service du développement prioritaire de la collectivité de la grande zone montréalaise. Elle fut donc traitée différemment. Le gouvernement a ainsi engendré son sous-développement. En droit, cela contrevient expressément à l'article 15 de la Charte constitutionnelle.

La portée d'étiquettes telles "quelques arpents de neige", "peuple sans histoire ", "régions ressources"

Dans le cadre de la Constitution canadienne l'étiquette, le classement ou la catégorisation des individus et des groupes sont proscrits.

Chaque citoyen doit être traité également à tous les autres par le gouvernement et par l'État. Toute personne ou groupe (région) ne peut voir sa dignité et sa liberté atteintes par l'imposition de désavantages, de stéréotypes et de préjugés politiques et sociaux. 
Cette personne ou ce groupe doit être traité et reconnu par la loi ou l'effet de la loi, politique, programme, comme un être humain et membre égal de la société, tout aussi capable, méritant le même intérêt, le même respect et la même considération.

En droit, il est constitutionnellement intolérable qu'au Québec l'individu et son groupe aient été classés, catégorisés, étiquetés. Il est par conséquent inacceptable qu'il découle une différence de traitement traduisant une application stéréotypée de présumées caractéristiques de groupe ou que cette différence perpétue ou favorise l'opinion que le groupe ou l'individu visé est moins capable ou digne d'être reconnu et valorisé en tant qu'être humain ou membre égal de la société.

Étant donné que de tels énoncés s'appliquent ne serait-ce qu'en partie à notre situation de collectivité citoyenne habitant une région qui ne fait pas partie de la grande zone montréalaise, force est alors de conclure que le terme "région ressource " constitue une étiquette. Face à la Constitution, une telle étiquette, parce qu'elle entraîne un traitement différent, doit être dénoncée et combattue.

Après l'Approche commune, quelques milliers d'amérindiens, même si leur droit à un traité repose aussi sur des hypothèses, entre autres historiques, auront entre leurs mains les outils éprouvés pour assurer leur développement durable. Il est vrai, comme ils l'affirment, qu'ils iront rejoindre le niveau de développement des «Blancs» (sic). Il faut cependant comprendre que les Blancs dont ils parlent sont ceux de la grande région de Montréal et nullement nous-mêmes qui avons bâti les régions du Saguenay-Lac-Saint-Jean et de la Côte-Nord.

- Considérant qu'à l'instar de la politique des régions, l'Approche commune est une action gouvernementale basée fondamentalement sur notre exclusion des bénéfices de la Constitution canadienne;

- Considérant que contrairement à la politique des régions elle s'inscrit dans une démarche prétendue de satisfaction et de 
protection constitutionnelle de droits destinés à un groupe ciblé et exclusif : les Amérindiens ;

- Considérant qu'elle constitue une négation du fait que nous aussi avons besoin des protections de notre Constitution;

Il en découle, nécessairement et logiquement, que l'évaluation de leur bien-fondé ou leur analyse doit tenir compte de l'ensemble des droits fondamentaux constitutionnalisés en 1982 et que l'action gouvernementale doit s'appliquer aux collectivités des «régions ressources $»$.

Pour conclure, il serait difficile de ne pas remarquer que l'action gouvernementale dans l'adoption de l'Approche commune démontre quatre évidences lourdes :

1. Le gouvernement reconnaît ainsi que le développement - celui qui corrige les écarts entre les collectivités - est de sa responsabilité et qu'à ce titre, il dispose de tous les outils pour créer les conditions permettant à une collectivité de se développer.

2. Conséquemment, la mise en place des conditions et des leviers qui rendent possible le développement est avant tout Affaire d'État et non, à priori, celle des individus et de l'entreprise privée.

3. Au Québec, le développement relève d'une volonté politique arbitraire, au bon plaisir des gouvernants et sans égard à la loi fondamentale du pays.

4. Le gouvernement serait capable, à l'endroit de la majorité régionale canadienne française, de faire preuve du même zèle qu'il déploie résolument envers la minorité amérindienne. C'est contraint par la force démocratique populaire ou par les tribunaux que l'État devra reconnaître à la majorité les mêmes droits qu'à la minorité amérindienne. 
Toutes les collectivités régionales se verront-elles appliquer également leur droit fondamental à l'égalité effective des chances économiques? Assisterons-nous à la consécration de la volonté gouvernementale québécoise de continuer à déporter vers la grande région de Montréal la collectivité canadienne française des régions illégalement étiquetées «ressources», traitées différemment et appauvries? Aux hypothèses sociales, économiques et historiques qui tiennent actuellement lieu de politique, ajoutera-t-on des hypothèses nous confirmant encore dans le maintien de droits fondamentaux inférieurs?

L'Approche commune pose crûment ces incontournables questions. La réponse finale appartient à plus de 350,000 citoyens de la Côte-Nord et du Saguenay-Lac-Saint-Jean, orphelins de leurs représentants élus et des autres institutions démocratiques. 


\title{
Chapitre II
}

\author{
L'identité fondamentale des \\ peuples autochtones du Canada
}

$\underline{\text { Retour à la table des matières }}$

Quels sont donc dans la Constitution, ces «peuples autochtones du Canada»? Pourquoi l'article 35. (2) dit-il: «peuples autochtones du Canada» s'entend notamment des Indiens, des Inuits et des Métis du Canada »? Pierre Elliott Trudeau, le Père de la Constitution canadienne de 1982 écrivait à ce sujet :

\begin{abstract}
«Si nous avions tenté d'identifier chacune des minorités vivant au Canada et de protéger toutes les caractéristiques qui en faisaient un groupe à part, nous aurions à coup sûr précipité le démembrement du territoire canadien. Ce danger eût été particulièrement grand dans le cas de collectivités qui eussent pu se réclamer d'une partie déterminée de ce territoire, par exemple les Celtes en Nouvelle-Écosse, les Canadiens français au Québec, les Acadiens au NouveauBrunswick, les Indiens et les Inuits dans le Grand Nord. C'est pourquoi les articles 25 et 35 concernant les peuples autochtones (comme d'ailleurs la clause 27 sur le multiculturalisme et à plus forte raison la clause 15 sur les minorités de toutes sortes) évitent toute identification entre ces collectivités et un gouvernement en particulier » (Trudeau, 1990).
\end{abstract}

Nous aurons compris que ces «peuples autochtones du Canada» auxquels réfère Trudeau proviennent pour l'essentiel de deux souches ancestrales.

Les uns sont de souche européenne. Ils sont originaires par voie ancestrale du pays qu'ils ont nommé et qu'ils habitent. Ils sont les 
descendants ancestraux des premiers arrivants européens. Leurs ancêtres - avant l'affirmation par sa Majesté de sa souveraineté étaient présents sur un territoire identifié. Il s'agit, entre autres, des Canadiens français du Québec, des Acadiens du NouveauBrunswick et des Celtes de la Nouvelle-Écosse. Les autres sont de souche amérindienne. Depuis des temps immémoriaux, la descendance de chaque tribu et de chaque groupe est ancestrale. Il s'agit des Indiens, des Inuits et, plus récemment, des Métis du Canada.

\section{"Autochtone" is a french word}

Autochtone est un mot de la langue française, l'une des deux langues officielles reconnues par la Constitution du Canada (Constitution 1982, article 16). Ce mot signifie dans les dictionnaires qui font autorité en français: "Originaire du pays qu'il habite ». Au sens du dictionnaire français universel, je suis et nous sommes des autochtones. La Constitution canadienne confirme cette assertion en ne proposant pas de définition du terme différente de celle contenue dans les dictionnaires français.

Elle le confirme aussi dans le libellé français de l'article 35. On y lit: «(2) Dans la présente loi, «peuples autochtones du Canada » s'entend notamment des Indiens, des Inuits et des Métis du Canada. ». Comment comprendre autrement l'utilisation du terme « notamment» qui signifie « entre autres » avant que soit désigné comme autochtones les Indiens, les Inuits et les Métis? Il s'agit donc d'un énoncé inclusif par opposition à un énoncé exclusif.

En 1982, le Parlement canadien désirait clarifier certains énoncés relatifs aux indiens dans la Constitution de 1867. À la recherche d'une meilleure protection des droits des Amérindiens et devant la gravité de leur situation dans l'Ouest du pays, il fut déterminé que, dans la loi constitutionnelle, le qualificatif " peuples autochtones $d u$ Canada ", s'entendait notamment des Indiens, des Inuits et des Métis du Canada. Puisque chacun de ces peuples était réputé être par voie ancestrale, " originaire du pays qu'il habite » et que parmi 
eux, des peuples habitent le pays depuis les origines. Aussi, puisque leurs intérêts risquaient d'être négligés au sein de l'État canadien renouvelé, le Parlement désirait simplement mieux protéger au sein de la société canadienne, les valeurs, coutumes et traditions de ces ensembles de personnes habitant d'une manière ancestrale un même territoire et formant une même nation. Il faut aussi savoir que puisque désormais, tout le Canada appartenait à chaque citoyen, le législateur ne désirait nullement amorcer l'édification d'un pays morcelé en autant de territoires restreints qu'il y a de groupes ethniques, culturels, et autres qui auraient été tentés de s'identifier à un territoire donné (Trudeau, 1990).

Touchant la définition à partir de 1982, des droits existants ancestraux ou issus de conventions écrites entre sa Majesté et certaines de ces entités politiques, il appartiendrait "aux tribunaux de faire l'interprétation juridique des faits ${ }^{6}$. Ce fut aussi cette même année que les Amérindiens du Canada se virent donner, par la Constitution et par la Charte canadienne des droits et libertés, toutes les possibilités imaginables - sauf le retour en arrière - pour enfin intégrer la société, tout en conservant leurs valeurs, coutumes et traditions.

6 Voir à ce sujet les débats des Communes de novembre 1981. 


\section{Vision d'interprètes diplômés}

Le paragraphe 2 de l'article 35 déclare que l'expression «peuples autochtones du Canada» au sens de la Loi constitutionnelle s'entend « des Indiens, des Inuits et des Métis du Canada » (Lysyk, 1982).

Contrairement à Trudeau, ce constitutionnaliste ne se préoccupe pas de l'expression "s'entend notamment » contenu dans le texte constitutionnel. Il affirme que le but de l'énoncé constitutionnel s'adresse seulement aux autochtones de souche amérindienne. Pour lui, l'expression "s'entend notamment» qui figure dans l'article 35, veut dire «au sens de la Loi constitutionnelle s'entend ...». Si tel était le cas, pourquoi ne pas avoir utilisé le terme «s'entend seulement» ou un énoncé mettant clairement en lumière l'exclusion d'autres autochtones?

\section{Autre vision}

«Deux choses valent d'être soulignées au sujet de la garantie offerte [par l'article 35]. D'abord, elles concernent les droits existants, ce qui devait normalement être déterminé au moment de l'entrée en vigueur de la loi en 1982, sous réserve des droits territoriaux mentionnés. Ensuite, la garantie fait mention des peuples autochtones, une notion qui constitue l'un des ingrédients du droit à l'autodétermination en droit international. Un tel droit à l'autodétermination a d'ailleurs été spécifiquement reconnu aux autochtones du Québec par une résolution de l'Assemblée nationale en mars $1985 \ldots$ Pour l'instant toutefois, les revendications autochtones se rapportent seulement à l'autonomie gouvernementale et non à la souveraineté » (Pilette, 1993).

Face à l'identité des autochtones, le citoyen canadien ordinaire qui a simplement compris l'âme de sa Constitution est placé devant une situation déchirante. Doit-il comprendre que pour assurer sa survie à titre de membre d'une minorité étiquetée « région ressource », il est convié à se prêter à un bas calcul ?

À l'instar des leaders amérindiens, devrait-il, par ses agissements, aller à l'encontre de la Constitution canadienne, en se montrant 
juste assez canadien pour en arriver à infléchir les institutions en sa faveur, mais pas assez pour exiger que ses gains éventuels bénéficient également à tous les autres canadiens ?

Pour la réalisation de son plan, s'il opte pour son exclusion, devrat-il exiger d'être reconnu comme un autochtone, tout en espérant que les Acadiens du Nouveau-Brunswick, les Celtes de la NouvelleÉcosse et d'autres minorités qui s'identifient à un territoire ne décident d'en faire autant?

Bref, optera-t-il pour un Canada à deux étages : un Canada dans lequel les citoyens sont égaux mais après que les autochtones ou premières nations aient été servis?

Que l'expression peuples autochtones du Canada soit exclusive ou inclusive à notre égard, à moins que nous ne remettions vitement notre Constitution en marche, autant la politique régionale que l'Approche commune auront pour effet de nous confiner à jamais à l'inégalité des chances, en nous dépossédant de nos droits fondamentaux.

Dans le contexte où les Innus sur leur Nitassinan seront en voie de devenir un État moderne - souvenain - englobant nos régions, à quelles nouvelles dépossessions seront soumises les générations futures ? Y aura-t-il un endroit assez loin dans ce vaste monde pour que les archéologues et les historiens qui, en échange de subvention innues, ont établi les frontières absurdes du pays Innu, puissent aller se cacher et se faire oublier?

S'agit-il là d'une situation carrément impossible ? Bien sûr que non! Car l'histoire de l'humanité nous a largement enseigné que tout nationalisme ethnique, conduit tôt ou tard à la volonté de proclamer l'indépendance d'un peuple sur un territoire donné et souvent, au fil des décennies, à étendre le territoire dont la Nation se dit propriétaire. De nombreux conflits armés le démontrent à chaque jour. 
Bref, nous sommes face à un dangereux imbroglio créé par le Parlement canadien. Ce dernier a été mal avisé de s'être livré à l'identification, dans la Constitution modernisée de 1982, de peuples qui, ultérieurement, ont su tirer profit d'un mauvais gouvernement, de son aristocratie et de la complicité d'universitaires, pour réclamer un statut spécial, pour emprunter la voie exactement inverse à celle tracée par la Constitution : celle de l'intégration avec garantie de liberté dans l'égalité des chances pour l'épanouissement de l'individu et de son groupe d'appartenance.

À ceux qui, parmi nous, tiennent à tout prix à ne pas se préoccuper des lendemains d'une Approche commune née de décisions contraires à l'esprit de la Constitution, j'adresse les interrogations suivantes :

- Êtes-vous si certain que l'Approche commune n'est pas le plus parfait ferment pour la promotion de l'indépendance nationale des Innus sur le territoire de notre région qu'ils sont en voie de faire leur?

- Êtes-vous si certain qu'il n'y a pas lieu de s'inquiéter d'énoncés comme celui qu'avançait sérieusement le journal La Presse : «... qu'on le veuille ou non, le déclin de certaines régions et villages est déjà fortement avancé. Quant à ceux qui prôneront l'importance d'occuper le territoire, il faudra prendre note que notre occoumène* occupe à peine un faible pourcentage de la province, ce qui nous pousse d'ailleurs à le rétrocéder aux peuples autochtones ... Murdochville ne doit pas être vu comme un cas d'exception, mais une occasion de réfléchir sérieusement, plutôt que de façon complaisante, sur le déclin des villes moyennes régionales » (Gill, novembre 2002). 


\section{Chapitre III}

\section{La cession de nos droits et de notre territoire : trois objections de fond}

Comme collectivité, nous sommes confrontés à la cession illégale de nos droits fondamentaux à l'égalité des chances au profit de la grande région montréalaise et à une récidive, la cession de nos droits et de notre territoire régional à la faveur des seuls autochtones amérindiens. Trois objections fondamentales se posent à cette cession de nos droits protégés par la Constitution. Même prises individuellement, n'importe laquelle de ces objections suffirait à invalider l'action du gouvernement touchant l'Approche commune ou sa politique des régions.

\section{Première objection}

La plus importante objection découle du fait que, depuis le début des années 1970 et plus particulièrement depuis l'adoption de la Constitution canadienne ${ }^{7}$, les collectivités de la région du

7 Dès avant 1982, le Québec violait des principes universellement reconnus (Charte de l'ONU). Après 1982, ces mêmes principes devenaient consacrés comme fondamentaux dans la Constitution canadienne. 
Saguenay-Lac-Saint-Jean et de la Côte-Nord ${ }^{8}$ se sont vues soustraites par le gouvernement du Québec, à l'application des articles 7 et 15 de la Charte constitutionnelle canadienne des droits et libertés ${ }^{9}$. Il en fut de même de l'application de l'article 36. (1) a) de la Constitution canadienne. Le premier, l'article 7, définit le droit du citoyen de naître et de prospérer librement et également dans sa communauté d'appartenance. Le deuxième, l'article 15, renvoie au droit à l'égalité sociale des chances sans discriminations. Le troisième, l'article 36. (1) a), inscrit le droit à l'égalité régionale des chances au plan économique.

\section{Point de vue de constitutionnaliste}

«Et voilà qui va au cœur du problème. La Charte existe pour empêcher les abus de pouvoir (par les gouvernements ou par les individus privilégiés qui se trouveraient en position d'autorité), afin que toute personne puisse s'épanouir librement au sein de la société civile. Mais elle n'a pas pour fonction de rendre les gouvernements plus intelligents ou mieux avisés, ni de leur insuffler une quelconque orientation idéologique. Cela, c'est l'affaire des élus et de ceux qui les élisent.

Notre Charte, comme d'ailleurs notre Constitution, présuppose et garantit l'exercice de choix démocratiques par les électeurs. Mais c'est à ces derniers qu'il revient d'élire des gouvernements qui feront "les lois, programmes ou activités destinés à améliorer la situation d'individus ou de groupes défavorisés " et à favoriser "le développement économique pour réduire l'inégalité des chances »(clauses 15. (2) et 36. (1) b)).

$8 \mathrm{Au}$ total, il $\mathrm{y}$ a au moins 6 régions ainsi brimées dans leurs droits fondamentaux.

9 «En avril 1982, l’Assemblée Nationale du Québec adoptait une loi de dérogation générale des lois québécoises, [dont la Charte québécoise des 
[...] Or les lois et politiques qui sont faites pour donner suite à ces objectifs doivent s'appliquer également à tous (clauses 15.(1) et 28) » (Trudeau, 1990). De plus, la clause 6 et plus tard en 1989, en matière de droits économiques et sociaux, (Arrêts Irwin Toy et Slaight, Godbout, 1997), la clause 7 donnaient aux Canadiens le droit d'établir leur résidence et de gagner leur vie n'importe où au pays.

À l'évidence, cela signifie que le gouvernement n'avait aucun droit de mettre la région au service du développement prioritaire de la grande région de Montréal. Par le maintien du sous-emploi dans les « régions ressources", il s'arrogeait le droit d'agir de manière à contraindre les jeunes à l'exode. Il n'avait pas le droit de concentrer les fruits de l'exploitation des ressources naturelles régionales, la richesse collective et les emplois, en trop grande part, dans une seule région élue.

Formellement depuis 1982 et en raison de la Constitution, le gouvernement n'avait plus le droit de donner seulement et prioritairement à la grande région de Montréal des outils et des leviers de développement qu'il refusait dans les faits aux régions illégalement étiquetées « ressources ». Il n'avait plus le droit de préconiser pour la moitié des régions du Québec, un traitement différent de celui qu'il accordait aux collectivités de l'autre moitié des régions, soit les territoires composant la grande région de Montréal. Dans pareil contexte, il n'est pas étonnant que le gouvernement du Québec ait toujours claironné publiquement ne pas vouloir signer la Constitution de 1982. Ce qui fait croire à beaucoup de citoyens que celle-ci ne s'applique pas au Québec. Pourtant, la charte canadienne

droits et des libertés de la personne] aux articles 2 et 7 à 15 de la nouvelle Charte canadienne des droits et libertés » (Pillette, 1993). 
«s'applique incontestablement aux législatures et aux gouvernements provinciaux ...» (Godbout \& Longueuil, 1997). En effet, la Constitution canadienne s'applique aux citoyens du Québec. Plusieurs jugements le démontrent.

Depuis juillet 2000, date où fut connue publiquement l'Approche commune, nous comprenons que le gouvernement compte récidiver. Il s'apprête à poser le même geste discriminatoire que celui posé en 1970, geste qu'il a illégalement maintenu en dépit de l'adoption de la Constitution en 1982. Cette fois-ci, par sa politique et par l'effet de son action, il a décidé ${ }^{10}$ de privilégier les collectivités autochtones amérindiennes de la région du Saguenay-Lac-Saint-Jean et de la Côte-Nord. L'affront de 1970, réitéré en 1982, se répètera à nouveau à l'endroit de ces deux régions par le truchement du futur traité amérindien découlant de l'Approche commune.

En marge de cette objection, notons que si les collectivités canadiennes-françaises des "régions ressources» étaient aussi développées, favorisées et prospères que la grande collectivité montréalaise dans le contexte strict des droits à l'égalité des chances économiques entre les régions - et mis à part la faiblesse

10 Aux yeux de la Cour suprême du Canada, pour juger d'une discrimination, il faut rechercher et étudier davantage les effets de l'application de la loi sur les individus et leur groupe d'appartenance, que la manière dont la loi est écrite. Par loi, on entend par exemple, l'ensemble des lois et politiques qui constituent la politique de développement économique régional. Il en est de même pour un traité. La jurisprudence à ce propos est abondante. Aussi, la Cour accepte qu'aux motifs cités de discrimination, s'ajoutent des motifs analogues. Même si elle n'apparaît pas nommément dans la liste des motifs interdits de discrimination, la discrimination fondée sur la condition sociale liée à la région d'appartenance pourrait fort bien être valide, d'autant plus que les effets sur les collectivités sont graves au point qu'ils entraînent la désintégration du tissus socioéconomique des collectivités humaines des régions ressources. 
dans la preuve historique des Amérindiens - il y aurait éventuellement moins d'éléments à objecter à l'Approche commune. Mais ce n'est pas le cas: notre niveau de développement économique régional n'est guère plus enviable que celui de nos voisins amérindiens. Comme eux, nous sommes sous-développés par comparaison à la grande zone montréalaise. Par l'Approche commune, le gouvernement récidiviste ne peut pas, pour une seconde fois, propulser une collectivité, cette fois les Amérindiens, vers leur développement en laissant pour compte une autre fois les Canadiens français de nos régions. Depuis 1982, la Constitution, par son article Premier et par son article 15, interdit formellement telle pratique discriminatoire et lui commande de s'en justifier.

Il importe aussi de comprendre une autre donnée constitutionnelle de notre problème. Elle réside dans le fait que le droit à l'égalité du citoyen et de son groupe d'appartenance, sa collectivité humaine régionale par exemple, fait partie de la famille des droits qui appartiennent uniquement et exclusivement à chaque citoyen ${ }^{11}$.

«... la Charte canadienne ... allait aussi beaucoup plus loin. Située dans la grande tradition de la Déclaration des Droits de l'homme et du citoyen de 1789 et du Bill of Rights des États-Unis d'Amérique de 1791, elle établissait implicitement la primauté de la personne sur l'État et sur toutes les institutions gouvernementales ... tous les membres de la société civile jouissent de certains droits fondamentaux inaliénables et ils ne peuvent en être privés par aucune collectivité (État, gouvernement) ni au nom d'aucune collectivité (nation, ethnie, religion ou autre). Il s'ensuit que seule la personne

11 Ce principe est celui de l'inaliénabilité des droits. Ces droits sont tellement fondamentaux que la philosophie de la démocratie les considère comme inaliénables; c'est-à-dire que pour que la participation de tous les citoyens à la politique commune soit assurée et efficace, chaque citoyen doit rester dépositaire de ces droits indépendamment des lois. 
humaine est porteuse de droits; la collectivité peut seulement détenir ces droits qu'elle exerce en fiducie pour ses membres et à certaines conditions. C'est ainsi que l'État, qui constitue la collectivité suprême sur un territoire donné, et ces organes de l'État que sont gouvernements, législatures et tribunaux, se trouvent limités dans l'exercice de leurs fonctions par la Charte et par la Constitution qui l'enchâsse" (Trudeau, 1990).

Le gouvernement, à la suite d'une élection, ne devient que le mandataire, l'emprunteur de ces droits. Il ne peut en disposer qu'au nom $\mathrm{du}$ citoyen et à des fins qui servent tous les citoyens, sans distinctions aucunes. S'il désirait continuer à agir en violation flagrante des droits fondamentaux des citoyens des régions qu'il a étiquetées « ressources », le gouvernement devrait nécessairement ouvrir la Constitution et en faire l'inscription par l'ajout d'un texte clair et net ${ }^{12}$.

En effet, la Constitution est la convention collective fondamentale entre les citoyens et le Canada, le Québec ou tout autre province. Depuis 1982, compte tenu de la Constitution, le gouvernement ne peut plus disposer comme bon lui semble des droits des citoyens, notamment en réponse au lobby de puissants groupes de pression.

N'en déplaise à certains représentants de la grande région de Montréal ou n'en déplaise aux citoyens canadiens amérindiens, le gouvernement doit développer aussi l'économie des régions étiquetées «ressources» traitées différemment d'autres régions du Québec depuis 1970 et bientôt, traitées différemment des collectivités amérindiennes. En matière de différence de traitement notons

12 Pour mieux saisir comment la Cour suprême intervient face à une discrimination non prévue dans une Charte provinciale, voir les mesures correctrices imposées au gouvernement de l'Alberta dans l'Arrêt Vriend, 1998. 
par exemple : les niveaux d'emplois maintenus inférieurs, les bilans migratoires négatifs, la dépopulation en découlant. Bref, toute région et toute collectivité locale devrait être en mesure d'assurer à chacun des jeunes qui y vivent, des chances égales de demeurer dans sa communauté, d'y prospérer et de s'y épanouir économiquement et socialement.

\section{Deuxième objection}

La deuxième objection repose sur le fait qu'au sens de la Constitution, les peuples autochtones du Canada seraient composés autant des Canadiens français du Québec, des Acadiens du Nouveau-Brunswick et des Celtes de la Nouvelle-Écosse, que des Indiens, des Inuits et des Métis. Le fait d'associer l'article 35 seulement à ces trois derniers groupes, constituerait une erreur grossière. Dans le contexte des droits fondamentaux reconnus à tous et à toutes par la Constitution, il ne pourrait être donné aux seuls Amérindiens le droit de se développer. D'autre part, par l'effet de sa politique des « régions ressources », le gouvernement ne peut continuer d'empêcher le développement des collectivités canadiennes-françaises vivant à proximité d'Amérindiens.

En dépit des obligations créées par ces dispositions constitutionnelles, le gouvernement, en se prêtant à une distinction néfaste entre autochtone et non autochtone, s'apprête quand même à agir. En vertu de l'article 25 de la Constitution, le peuple autochtone canadien-français du Québec sera donc contraint de se prêter à ce pitoyable jeu. Puisqu'ils ont les mêmes besoins que leurs voisins amérindiens, les citoyens canadiens français pourraient poser une exigence fondamentale conforme à l'esprit même de la Constitution (basée sur la solidarité par le partage et sur la liberté par l'égalisation des chances entre les collectivités et régions); ils pourraient 
réclamer que leur soient reconnus aussi les mêmes droits et libertés issus de la Constitution et de sa Charte. Dans le cadre des articles 35 et 25 , il appert qu'un peuple non autochtone ne pourrait poser une telle exigence; par contre, un peuple constitutionnalisé à titre d'autochtone pourrait demander au plus haut tribunal de statuer sur la question. L'ambiguité qui devrait être impérativement clarifiée tient au fait que l'article 25 prévoit que les droits garantis par la Charte ne doivent pas porter atteinte aux droits des peuples autochtones. Par exemple, si un avantage est accordé aux peuples autochtones en vertu de traités ou autre, les personnes qui ne reçoivent pas cet avantage ne pourraient pas faire valoir que leurs droits à l'égalité, énoncés à l'article 15 de la Charte ont été enfreints. La question à résoudre serait alors la suivante : en matière de droits économiques et sociaux, qu'arrive-t-il lorsque les Canadiens français sont reconnus comme faisant parti des peuples autochtones du Canada et qu'ils réclament que leur collectivité régionale bénéficie des mêmes mesures que celles contenues dans un traité ou autre?

Mais mieux encore, nous pourrions opter pour une valeur sûre, égalitaire et inclusive conforme à l'esprit de notre constitution. Les deux peuples autochtones régionaux pourraient aller plus loin ensemble, sans distinction de race, solidairement devant leur sousdéveloppement respectif et fraternellement en vue du développement. Il est pensable de faire mieux que de se placer sous la protection de l'article 25 : ils pourraient plutôt demander la mise en fonction de la protection plus générale des articles 15. (1) et 15. (2) de la Charte constitutionnelle.

- Par la première partie de l'article 15 , les deux collectivités pourraient exiger du gouvernement l'application réelle, effective et prioritaire de leurs droits fondamentaux en matière d'égalité économique des chances par comparaison aux droits déjà 
reconnus et effectivement accordés à la grande collectivité montréalaise.

- Par la seconde partie de l'article 15, ils pourraient combattre tout programme, toute mesure ou toute loi dont l'effet avantage déjà, socialement et économiquement, la collectivité de la grande région de Montréal, au détriment des droits de la collectivité globale autochtone de nos régions moins développées.

\section{Troisième objection}

Enfin, même si elle ne découle pas de la violation des droits fondamentaux à l'égalité des chances, une troisième objection doit être relevée. Elle invalide l'Approche commune dans ses fondements légaux, malencontreusement et trop sommairement encadrés par un article 35 isolé du reste de notre Constitution. De plus, elle contribue à montrer que ce gouvernement s'est arrogé, en toute illégalité, un droit de vie ou de mort sur des collectivités régionales sur la base d'hypothèses et d'approximations. Cette objection supplémentaire réside dans le fait qu'il est maintenant prouvé que l'Approche commune repose sur des hypothèses historiques plutôt que sur des faits constitutifs d'une preuve en matière de droits ancestraux. En effet, dans l'Approche commune, aucune des obligations édictées par la Cour suprême du Canada en matière de preuve de droits ancestraux et de titre aborigène n'est valablement satisfaite.

\section{Jugement d'un historien affranchi}

"Grâce à un habile bricolage de l'histoire des Montagnais du Québec qui ne résisterait pas à l'épreuve d'un questionnement serré, grâce à la trahison de l'État provincial et à la complicité $d u$ gardien fédéral de la Loi suprême du Canada, le 
gouvernement du Québec, le gouvernement d'Ottawa et les négociateurs des quelques 4567 citoyens ilnutsh habitant "notre terre » commune, manœuvrent pour contourner les lettres de la loi constitutionnelle, détournent l'esprit qui l'a fait concevoir et naître, et dérogent ainsi au principe fondamental de l'égalité des droits et des chances reconnus à tous..." without discrimination »; ce qui aura pour conséquences immédiates et perverses de dépouiller les 275,000 autres citoyens $d u$ Saguenay-Lac-Saint-Jean de leurs droits constitutionnels inaliénables, de s'emparer des richesses naturelles $d u$ territoire qu'ils entendent se partager entre eux - notre héritage -, d'en faire des étrangers sur leur propre terre, de les détourner de la juste part de ce qui leur revient en tant que fils et filles de ce "pays intime», et de perdre en bout de piste le combat pour la survivance sur ycelle ».

Russel Bouchard «L'Approche commune », 2002

Or, il appert qu'en matière de droits ancestraux, comme c'est le cas en matière de droits de la personne, une absence de preuve (la preuve reposant elle-même sur des faits) entraîne une absence de droit $^{13}$. Le préambule de l'Approche commune est éloquent sur ce défaut de preuve :

"Attendu que dans l'état actuel du droit, on ne peut dire avec exactitude quelle collectivité innue est titulaire de droits ancestraux, y compris le titre aborigène [titre particulier de possession du territoire] et que les parties s'entendent pour déterminer pour l'avenir quelle communauté innue exercera les droits reconnus, confirmés et protégés pour le traité» (Approche commune, 2002).

De surcroît, puisque nous traitons d'hypothèses, il faut aussi noter qu'en matière d'aménagement $\mathrm{du}$ territoire et en matière de

13 Il s'agit ici de la règle du « due process of law ». 
développement économique, démographique et social, la politique québécoise des « régions ressources » est également fondée sur des suppositions ou pire sur la conviction acharnée que l'hypothèse reste valable en dépit de la catastrophe observable et vérifiable. Depuis 1986 au moins, de nombreux travaux, en particulier ceux de Charles Côté ont démontré sur la base des données officielles les résultats désastreux des hypothèses appliquées (CASF, 1986; Désintégration des régions, 1991; Radiographie d'une mort fine, 2000). S'il était forcé d'appliquer les droits fondamentaux garantis par la Constitution, le gouvernement devrait cesser de gouverner par suppositions. Il devrait cesser de faire porter ses échecs par les collectivités régionales. Il ne pourrait, de plus, continuer à se disculper et à gouverner les collectivités comme s'il était le maitre propriétaire et répartiteur - selon sa convenance ou selon son bon plaisir - des droits fondamentaux.

Pour continuer à prétendre édifier un Québec indépendant, ce gouvernement persiste dans "l'opérationnalisation » de ses hypothèses. Pour justifier de persister dans cette direction, il se voit obligé de maintenir sa non adhésion à une Constitution dont les principes sociaux et économiques éprouvés ne reposent nullement sur des hypothèses, des conjectures, des suppositions et des «à peu près ». S’il y adhérait, il serait obligé de cesser ses appréciations arbitraires des règles et obligations édictées par la Constitution du pays, pour y substituer plutôt les mêmes principes, règles et droits fondamentaux qui, ailleurs au Canada, ont donné leurs fruits.

À la lumière de ces constats constitutionnels indéniables en lien avec les faits observables de notre réalité, le véritable combat ne devrait pas reposer seulement sur l'annulation du projet de traité pour cause de défaut dans la nécessaire preuve historique. Il devrait viser aussi, surtout et à jamais, le rétablissement des deux collectivités régionales étiquetées « ressources», dans leurs droits fondamentaux à l'égalité sans discrimination. Avec un traité entre le 
gouvernement et les seuls Amérindiens, sans reconnaissance des droits de l'autre collectivité, plus que jamais, il en est terminé du Pays. Mais d'autre part, sans traité et sans reconnaissance des droits des deux collectivités, il en est également terminé du Pays. Donc, il est grand temps qu'en dehors des partis politiques et des autres pollueurs institutionnels et partisans, les citoyens posent des jugements sur les résultats, prennent rapidement les choses en mains et s'occupent enfin de leurs affaires de citoyens. 
Mario Tremblay, Le Saguenay-Lac-Saint-Jean. Réalité interdite. 


\section{Chapitre IV}

\section{La violation des droits fondamentaux des autochtones canadiens-français : contexte et ampleur}

$\mathrm{D}^{\mathrm{i}}$ ès le début des années 1970, les Canadiens voulurent faire du Canada un pays fort et uni. Ils voulurent le fonder sur la réalisation de l'Égalité des chances pour tous. Chaque citoyen aurait le droit d'établir sa résidence et de prospérer effectivement libre et égal dans n'importe laquelle des régions et localités. Quelques années plus tard, la Constitution de 1982 venait formellement confirmer cette valeur.

Dans le Québec du début des années 1970, le gouvernement québécois prit le chemin inverse à celui emprunté par les Canadiens des autres provinces. L'appartenance particulière à une région spécifique devenait le critère primordial pour que les citoyens puissent accéder à la réalisation pleine de la liberté par l'égalité des chances économiques régionales. Plus tard, les faits pertinents ne tardèrent pas à révéler les effets des inégalités maintenues entre les collectivités régionales (CASF, 1986). En effet, les retombées de l'effort solidaire des collectivités des régions étiquetées «ressources 》 n'atteignaient pas également l'ensemble de la société québécoise. Ces retombées se voyaient détournées et concentrées dans un Québec nouveau, redessiné à leur insu. Ses nouvelles dimensions géographiques, sociales et économiques étaient basées sur l'exclusion en fonction de la région d'appartenance. Sans aucun débat 
public, illégalement, le gouvernement avait revu et corrigé la carte humaine et économique du pays qu'il préconisait.

Aussi ignorantes que solidaires, les collectivités des régions étiquetées « ressources » travaillaient avec ardeur à l'édification du Pays nouveau. Leur imaginaire puissant et généreux, alimenté par les politiciens nationalistes faisait rêver ces collectivités d'un Pays qui, dans la réalité, leur était adroitement interdit. Ce Québec nouveau, elles le croyaient sans distinction pour tous. Trompées, exclues socialement et économiquement, elles étaient vouées à s'épuiser, à s'éteindre petit à petit, à bout de force. Sans le savoir ni le comprendre - dans ce Québec de toutes les exclusions hypocrites - elles avaient commis deux crimes :

- Elles étaient coupables d'avoir trop aimé le Pays imaginaire, de l'avoir cru inclusif et d'avoir pensé qu'elles le bâtissaient aussi pour elles-mêmes. Pour mieux l'édifier, ne laissaient-elles pas leurs enfants se soumettre à l'exode ? Ne laissaient-elles pas les fantastiques retombées de l'exploitation de leurs ressources naturelles régionales profiter à la région élue, la grande région montréalaise ? Ne laissaient-elles pas leurs économies locales se charger seulement et presque exclusivement de l'exploitation de la ressource?

- Quelques décennies plus tard, le même entêtement du même gouvernement leur enfonce dans la gorge l'Approche commune. Elles sont à nouveau " condamnées » pour un crime qu'elles ignorent avoir commis. Le verdict est simple : une fois encore, pour le profit d'une autre collectivité, leur Assemblée nationale et leur gouvernement les dépouillera.

Le voilà le pays des nationalistes indépendantistes et de tous les autres partis politiques qui, de temps à autre, au gouvernement, prennent la relève et sévissent à leur tour ! 
Pendant que la collectivité canadienne-française se meurt par perte de sa capacité de remplacement naturel, la collectivité innue se prépare à émerger en force. Cette dernière est jeune, agressive et dynamique. Surtout, elle est consciente des droits tissés autour des autochtones amérindiens. Elle en a fait sa propriété exclusive et les interprète à outrance. Capable d'obstruction systématique financée à même les deniers publics, elle table sur deux forces majeures. D'une part, elle sait qu'en matière de stratégie économique, le gouvernement a mis tous ses œufs dans le même panier: le grand panier montréalais. Elle sait qu'à coup de menaces, d'injonctions et de requêtes diverses devant les tribunaux canadiens et les instances internationales, elle peut mettre en péril la bonne marche de la croissance économique prioritaire de la grande zone Élue.

Pour les collectivités des régions du Saguenay-Lac-Saint-Jean et de la Côte-Nord, la soumission à l'Approche commune équivaudra à accepter à continuer à disparaître socialement et économiquement. Discriminées, appauvries, asservies, esseulées, morbides et incapables de défendre comme il se doit leurs intérêts et droits garantis par la Constitution, ces collectivités sont actuellement vouées à disparaître. Pourtant, en droit, les citoyens du Saguenay-Lac-SaintJean et de la Côte-Nord font partie intégrante de la société canadienne. Individuellement et collectivement, ils sont au cœur d'une société qui reconnaît la primauté de la personne sur l'État et sur les institutions gouvernementales. Contrairement à ce que les citoyens tolèrent, leur société régionale n'est fondée ni sur la primauté de la croissance du Grand-Montréal, ni sur la primauté de la collectivité innue, ni sur la primauté de l'aristocratie fidèle au Parti.

Compte tenu de la Charte constitutionnelle, s'il ose persister sur la trajectoire déjà empruntée, le gouvernement procédera alors à un abus de pouvoir. Par conséquent, il sera dans l'ordre naturel des choses que l'abuseur se trouve au plus tôt devant les tribunaux. 
Devant les juges et devant le peuple, il devra répondre de ses violations du principe constitutionnel de "l'égalité des chances économiques régionales ». En Amérique du Nord et dans toute démocratie digne de ce nom (lire ailleurs qu'au Québec), ce principe constitue l'abc du développement. L'article 36.(1) de la Constitution affirme que les "gouvernements fédéral et provinciaux s'engagent à promouvoir l'égalité des chances de tous les Canadiens ».

Par cette clause, il devient impossible aux collectivités plus fortes tant économiquement que politiquement - d'user avec la complicité du gouvernement, de leur supériorité pour empirer les conditions économiques, sociales et institutionnelles de collectivités plus faibles, à moins d'œuvrer dans l'illégalité.

Par respect de cette première règle, le gouvernement se devait depuis 20 ans, de favoriser le développement économique de chaque région, pour réduire l'inégalité des chances. Pour y arriver, sous la surveillance étroite des élus, les lois et programmes gouvernementaux devaient être appliqués de manière à soutenir le développement de tous, sans distinction fondée sur la race, la région d'appartenance ou sur d'autres caractéristiques personnelles et de groupe.

Dans le contexte de ce droit, le gouvernement ne peut continuer à affubler les régions du Saguenay-Lac-Saint-Jean, de la Côte-Nord et d'autres de l'étiquette « région ressource » (sic), pour le seul profit de la grande région de Montréal. Pour le seul profit de la collectivité innue, il ne peut accorder, à elle seule, les outils, droits et certitudes propres à générer un développement durable. 
Par sa politique d'exclusion à la faveur des seuls Amérindiens, le gouvernement viole une seconde règle constitutionnelle. Celle-ci est consacrée par l'article 15. (2) de la Charte constitutionnelle. En agissant de la manière précédemment décrite, le gouvernement va à l'encontre du principe de l'égalité devant la loi ${ }^{14}$. Le gouvernement ne peut, en effet, adopter en faveur d'une quelconque collectivité, des orientations, lois, programmes, traités, etc. dont l'effet serait d'interdire à d'autres collectivités déjà défavorisées l'amélioration, à elles aussi, de leurs conditions socio-économiques.

Dans un cadre plus large, en matière de violation institutionnalisée des droits des citoyens du «Québec des ressources », il en résulte une troisième violation. Celle-ci touche l'article 15. (1). Cet article constitutionnel est conçu pour attaquer les actions législatives dont l'effet serait d'opérer une différence ou une distinction de traitement comparativement à d'autres personnes ou à d'autres communautés. Ce serait le cas de la différence de traitement que réserve aux régions étiquetées «ressources», la majorité parlementaire issue de la grande région de Montréal.

\section{L'article 15. (1)}

"On pourrait affirmer que le paragraphe 15. (1) a pour objet d'empêcher toute atteinte à la dignité et à la liberté humaines essentielles par l'imposition de désavantages, de stéréotypes et de préjugés politiques ou sociaux, et de favoriser l'existence d'une société ou tous sont reconnus par la loi comme des êtres humains égaux ou comme des membres égaux de la société

14 Par loi, on entend l'ensemble de l'action gouvernementale qui constitue la politique de développement prioritaire de la grande région de Montréal, d'une part, et le futur traité découlant de l'Approche commune, d'autre part. 
canadienne, tous aussi capables, et méritant le même intérêt, le même respect et la même considération. Une disposition législative qui produit une différence de traitement entre des personnes ou des groupes est contraire à cet objectif fondamental ... » (Arrêt Law, 1999).

Il en serait de même de la différence de traitement, réservée par l'Approche commune, aux autochtones de souche européenne du Saguenay-Lac-Saint-Jean et de la Côte-Nord par comparaison aux autochtones de souche amérindienne. En vertu de cet article, un individu et son groupe d'appartenance ne peuvent être exclus des bénéfices d'un programme gouvernemental améliorateur réservé à certains alors que les faits démontrent que les besoins de ceux-là sont semblables à ceux du groupe visé par les bénéfices du programme. Si cela devait se produire, il en résulterait une atteinte à la dignité. En droit constitutionnel, elle est synonyme d'atteinte au droit à l'égalité garantie sans discrimination. Dans ce cadre, une politique économique québécoise ne doit donc pas avoir pour effet de laisser dans le sous-développement durable, la région du Saguenay-Lac-Saint-Jean, la Côte-Nord et les autres régions étiquetées « ressources » mises illégalement au service de la région la plus forte.

La dignité humaine telle qu'envisagée par les créateurs du paragraphe 15.(1) :

"...est bafouée lorsque des personnes et des groupes sont marginalisés, mis de côté et dévalorisés, et elle est rehaussée lorsque les lois reconnaissent le rôle à part entière joué par tous dans la société canadienne. Au sens de la garantie d'égalité, la dignité humaine $n$ 'a rien à voir avec le statut d'une personne dans la société en soi, mais elle a plutôt trait à la façon dont il est raisonnable qu'une personne se sente face à une loi donnée » (Arrêt Lovelace, 2000).

Outre l'illégalité constitutionnelle de la politique québécoise 
favorisant la grande région de Montréal, l'Approche commune constitue une seconde illégalité dont l'ampleur est comparable à la première. En effet, il appert qu'en terme de sous-développement économique, les collectivités innues et canadiennes françaises sont aux prises avec une situation somme toute similaire. Par conséquent, au chapitre des solutions, les deux collectivités éprouvent des besoins semblables. Dans ce contexte, en raison de l'article Premier de la Charte constitutionnelle des droits et libertés, le gouvernement aurait le devoir constitutionnel de justifier sa politique ${ }^{15}$.

- Considérant que la recette du développement est la même pour tous les peuples;

- Considérant que les outils, droits et certitudes juridiques nécessaires à leur satisfaction sont entre les mains du gouvernement;

Pour que soient valides les dispositions de la politique régionale et de l'Approche commune, il apparaît que, conformément à l'article Premier de la Charte constitutionnelle, deux conditions essentielles doivent être impérativement satisfaites :

1. L'objectif poursuivi - par la politique ou le traité -doit se rapporter à des préoccupations urgentes et réelles.

2. Dans l'objectif d'assurer l'égalité des chances économiques de tous, la concession, aux seuls Innus, d'outils, droits et certitudes doit être jugée raisonnable et se justifier dans une société libre et démocratique. C'est ainsi que devraient être appréciées les mesures menant à l'établissement d'une autonomie gouvernementale, à de nouvelles bases de relations

15 Il faut référer ici à la doctrine dégagée en cette matière depuis l'arrêt Andrews en 1989. La Revue du Barreau canadien, volume 79 (2000) en fait état. 
avec les autres gouvernements, à des moyens techniques, financiers et à une participation aux décisions et aux projets de développement.

$\mathrm{Si}$, en dépit des responsabilités et des obligations constitutionnelles, le gouvernement s'entête à imposer à nos régions le maintien de sa politique et un traité d'exclusion en faveur de la grande région élue et des Innus, il lui incomberait alors de prouver, selon la prépondérance des probabilités, que ses actions sont justifiées dans le cadre d'une société libre, démocratique et fondée sur la reconnaissance de la primauté du droit.

Donc :

1. Le fait d'accorder des droits à la collectivité montréalaise et innue, sans accorder l'équivalent à la collectivité canadiennefrançaise qui a, pour se développer, les mêmes besoins, doit avoir un lien rationnel avec le devoir constitutionnel d'amener toutes les « régions ressources » au même niveau de développement.

2. Le traité doit porter le moins possible atteinte aux droits garantis par la Charte constitutionnelle des droits et libertés. Dans ce cadre, puisque l'action donne aux uns en excluant d'autres qui ont le même besoin de développement, il y a donc atteinte aux droits.

3. Alors que le niveau de sous-développement des deux collectivités est comparable et commande les mêmes solutions, la recherche de la réalisation de l'égalité des Innus ne peut l'emporter sur la recherche de la réalisation de l'égalité des membres de la collectivité canadienne française. Elle doit être proportionnelle: à cette fin, elle doit donc englober les deux collectivités.

Enfin, en matière de violation des droits fondamentaux des citoyens de cette région, tout n'a pas été dit. Dans le cadre de la politique 
gouvernementale de croissance économique prioritaire de la grande région de Montréal, les citoyens des «régions ressources » assistent béats à la violation depuis 20 ans, d'un autre droit fondamental, objet de l'article 7 de la Charte constitutionnelle ${ }^{16}$. Cet article définit et protège une sphère limitée d'autonomie du citoyen. Dans cet espace légal constitutionnel, il est ordinairement interdit à l'État de pénétrer. Cette zone d'interdiction comprend des choix fondamentaux participant de l'essence même de ce que signifie la jouissance de la dignité et de l'indépendance individuelles. Au premier plan figure le droit de choisir un lieu pour établir sa demeure, travailler, fonder une famille et prospérer n'importe où dans le pays. Mis dans le contexte des régions étiquetées « ressources », chaque élément jeune de la société régionale jouit du droit fondamental et constitutionnel de trouver un travail qui lui convient et de demeurer librement et sans contraintes économiques, dans son milieu régional d'appartenance.

Il faut par conséquent comprendre que, depuis 1982, l'État québécois n'a plus juridiquement et démocratiquement le droit de continuer à contraindre - par le maintien constant d'un taux d'emploi régional inférieur à celui de la grande région de Montréal ${ }^{17}$

16 Contrairement à une croyance répandue, l'article 7 ne vise pas uniquement la protection des droits des citoyens en matière pénale ou criminelle.

17 Étant donné que le taux d'emploi du Québec est inférieur à la moyenne canadienne, la clause 6. (4) de la Charte permet au gouvernement fédéral d'élaborer des « programmes de promotion sociale en faveur des personnes socialement ou économiquement défavorisées. Ce qui est le cas prioritaire des citoyens des régions étiquetées «ressources» et de leurs frères amérindiens. Nous ne pouvons continuer à subir les discriminations, parce que l'article 15.(2) a pour fonction « d'améliorer la situation des personnes et de groupes défavorisés » (Dion, 1995). L'intervention du gouvernement fédéral étant d'autant plus motivée que notre situation de défavorisé découle de la violation systématique, par le gouvernement du Québec, de l'article 36 
- les citoyens d'une région étiquetée "ressource», en particulier ses éléments jeunes, à se soumettre à l'exode. Par une telle politique, illégalement, le gouvernement du Québec pénètre dans une sphère d'autonomie fondamentalement et essentiellement personnelle. Le droit fondamental de trouver un emploi à sa mesure dans sa région d'appartenance pour choisir librement de demeurer dans sa communauté, participe de l'essence même de ce que signifie la jouissance de la dignité humaine. Ainsi en ont décidé autant les tribunaux américains que la Cour suprême du Canada. La croissance prioritaire et orchestrée de la grande région montréalaise, au prix de l'exode des jeunes et au prix de la mise à mort sociale et économique progressive de régions entières, constitue une autre violation ouverte de la Constitution.

Dans la tradition juridique canadienne, la justice fondamentale vise premièrement à établir un juste équilibre entre les intérêts de la société et ceux des citoyens. Or, il est évident que la société québécoise n'est pas seulement la grande collectivité humaine montréalaise. Les «régions ressources » en font également partie. En droit, il apparaît que le développement de la région élue ne peut se réaliser au prix du sous-développement durable de nos régions. Tant que la Constitution demeure en force, jamais le développement d'une collectivité ne peut s'opérer au détriment du développement d'une autre collectivité, elle aussi sous-développée. Voilà l'une des facettes oubliées de l'âme du Canada et du contrat social fondamental entre les citoyens et les gouvernements fédéral et provinciaux.

de la Constitution canadienne garantissant notre droit à l'Égalité des chances économiques régionales. 
En droit constitutionnel, le développement régional est le nécessaire aboutissement de l'effet des politiques d'égalisation des chances. Dans le contexte canadien, les droits à l'égalité des chances étaient garantis sans discrimination aucune fondée, entre autres, sur la région d'appartenance ou sur la race. Le développement économique régional est, au premier chef, une responsabilité constitutionnelle de l'Assemblé nationale et du gouvernement. Contrairement à ce que les créatures administratives, comme les CRCD et les CLD laissent croire aux citoyens, ce n'est qu'en seconde instance lorsque les conditions fondamentales sont en place - que les organismes régionaux, les entreprises privées et les citoyens peuvent intervenir et faire leur part pour le développement. Les Élus du peuple ne peuvent, à l'encontre de la loi sur l'Assemblée nationale, laisser le gouvernement libre de procéder à une redistribution discriminatoire de la richesse collective et des emplois par le financement des programmes publics ${ }^{18}$. C'est depuis longtemps par ce canal principal qu'est favorisée la majorité privilégiée de la grande région montréalaise.

Indépendamment du droit touchant l'application de l'article 35. (1), le gouvernement a fait une démonstration éloquente dans le contenu de l'Approche commune et dans ses agissements : il a démontré qu'en matière de développement des collectivités, quand il veut agir efficacement, il le peut! Lorsqu'il a la volonté politique de procéder avec un zèle extrême à la reconnaissance de droits collectifs qu'il veut « fondamentaux » - une reconnaissance qu'il assortit des leviers de développement nécessaires - le gouvernement sait

18 Ces programmes regroupent la majeure partie des argents publics entrant dans les communautés. Ils constituent une série d'opérations qui, prises ensemble, devraient assurer le bien-être, l'égalité, l'équité et le développement au sein de chaque communauté. 
faire preuve d'une efficacité redoutable et sans borne. Il démontre qu'il procède à la sélection des collectivités qu'il désire développer et de celles qu'il abandonne, après en avoir extrait l'énergie vitale et les richesses au profit de ses favorites. Enfin, il fait la preuve que lui seul a le contrôle du débit de la valve contrôlant les droits économiques des citoyens par le truchement de la répartition des masses monétaires entre les collectivités des régions. 


\title{
Chapitre V
}

\author{
Des hypothèses, des choix \\ et des violations synonymes \\ de fermeture de régions
}

$\underline{\text { Retour à la table des matières }}$

- $\mathrm{n}$ matière de santé par exemple, nombre de Québécois ont en particulier dans les régions étiquetées « ressources » ${ }^{19}$. Cela est aussi le cas dans deux autres sphères d'action gouvernementale. La première a trait à la prétendue politique de développement économique régional. La seconde touche le règlement des revendications autochtones amérindiennes du Saguenay-Lac-Saint-Jean et de la Côte-Nord. Dans le premier cas, le gouvernement vogue depuis trente ans sur des hypothèses et des trahisons dont l'aboutissant consiste à cacher à la société des résultats néfastes. Quant à la seconde sphère, elle résulte de vingt années d'incurie en matière de droits des peuples autochtones du Canada.

19 La promotion de la santé des populations régionales va bien au-delà des simples soins hospitaliers. Elle inscrit la santé à l'ordre du jour des responsables politiques en les éclairant sur les conséquences que leurs décisions peuvent entraîner sur la santé et en leur faisant admettre leur responsabilité à cet égard. Le fait de s'occuper de la santé passe d'abord et avant tout par le développement économique des collectivités et des communautés humaines. (OMS, 1976). 
Des hypothèses économiques pour développer les régions

Retour à la table des matières

À partir de 1970, bien avant qu'il soit publiquement question des revendications des Amérindiens, le gouvernement de notre société avait amorcé, sans débat populaire, une politique de génération des inégalités entre les régions. Il avait adhéré à l'hypothèse qu'il n'y avait « rien de répréhensible à supprimer la pauvreté et le chômage dans une région peu développée en attirant la population dans une ville dynamique » (HMR, 1970). Pour provoquer le déplacement des éléments jeunes des régions vers la ville dynamique, il suffisait de créer et de maintenir le sous-emploi en dehors de la grande région métropolitaine, berceau de la ville « dynamique », Montréal.

En 1973, même s'il était informé que "c'est la créativité de toute une partie de la société qui risque d'être mise en veilleuse par l'épanouissement d'une "métropole» ou d'une "capitale» (OPDQ, 1973), le gouvernement rendait opérationnelle l'hypothèse de 1970 : d'une part, par la concentration dans les limites de la région élue, des emplois et de la richesse créés collectivement; d'autre part, par une politique régionale fondée sur des concepts alors à la mode chez les économistes distinguant "activités de croissance» et «activités de développement». Les premières étaient réservées à nos régions alors que les secondes étaient réservées à la région élue. On institua ainsi un des fondements importants de l'inégalité. 


\section{Vision d'économistes sur la société}

"Les activités de croissance sont à la remorque des innovateurs, elles assurent la conservation et le maintien des choses établies; les activités de développement par contre consistent dans des innovations qui transforment les conditions des opérations; elles sont des activités créatrices qui modifient les structures de coûts et de rendements ... C'est à Montréal que nous proposons de localiser principalement les activités nouvelles liées aux processus d'innovation: services financiers, sièges sociaux, services de transports, services d'expertise technique et administrative, centres de recherche privés et publics, industries de pointe, etc. En second lieu, dans le secteur manufacturier en général, la localisation à Montréal des activités nouvelles dont les facteurs de localisation exigent une présence dans l'agglomération proprement dite, particulièrement du point de vue des facteurs de complémentarité. Par contre, on encouragerait l'implantation des autres activités manufacturières (qu'il s'agisse d'activités nouvelles ou d'expansion importante, d'activités déjà établies à Montréal) à l'extérieur de la région métropolitaine, soit dans les autres villes de la région administrative de Montréal, soit à l'extérieur de Montréal» (OPDQ, 1973).

De supposition en supposition, le gouvernement s'était donc autorisé à appliquer à l'ensemble du territoire des concepts d'aménagement de l'espace économique et social, réputés applicables à l'espace urbain. Sans débat, il avait été déterminé que « La lutte aux disparités régionales a surtout un sens en terme de qualité de vie et non en terme de quantité, à moins que la société ne soit prête à tous les sacrifices, sinon à toutes les extravagances, pour répartir également, en nature et en nombre, toutes les activités sur tout le territoire »(OPDQ, 1973). Mais quelle était donc cette société mise en garde contre les coûts du sacrifice et l'extravagance consistant à se consacrer au développement égalitaire de toutes les régions ? Était-ce nous-mêmes vis-à-vis tout le Québec ? Était-ce plutôt la société montréalaise vis-à-vis le reste des régions du Québec? 
Ce que nous savons c'est que déjà en 1973, pour les planificateurs québécois du développement, « il était vain de penser que toutes les régions du Québec pourront connaître durant les 25 prochaines années un développement égal». S'il en était autrement, «le Québec aurait une tâche impossible à accomplir »(OPDQ, 1973). Il en était de même touchant la recherche d'un certain équilibre interrégional des populations: une "tâche impossible à accomplir » (OPDQ, 1973).

Quant à la consultation des populations réquisitionnées, de l'aveu de l'OPDQ, «les options à prendre ne peuvent l'être qu'après une consultation explicite et féconde de l'ensemble de la population puisqu'il s'agit par définition de choix collectifs et non de décisions technocratiques »(OPDQ, 1973).

C'est aussi en cette année 1973 que sont nées et qu'ont été consacrées, dans les concepts officiels, deux entités territoriales québécoises distinctes et tout à fait inégales en droit : le Québec de base et les régions ressources.

"Le développement [des régions ressources] repose davantage sur l'exploitation des ressources, en particulier les mines, la forêt et l'aménagement hydro-électrique. Ces types d'activités s'associent à une agriculture localisée dans les bassins ou vallées, et au tourisme de plein air. La population évaluée à 950,000 personnes et répartie d'une manière ponctuelle sur 570,000 milles carrés doit compter sur une mobilité périodique pour assurer sa subsistance. Le Bas SaintLaurent - Gaspésie, la Côte-Nord, le Saguenay - Lac SaintJean, le Nord-Ouest et le Nouveau-Québec sont les parties constituantes de ces régions »(OPDQ, 1973).

Figure I : Le Québec de base et les régions ressources. 


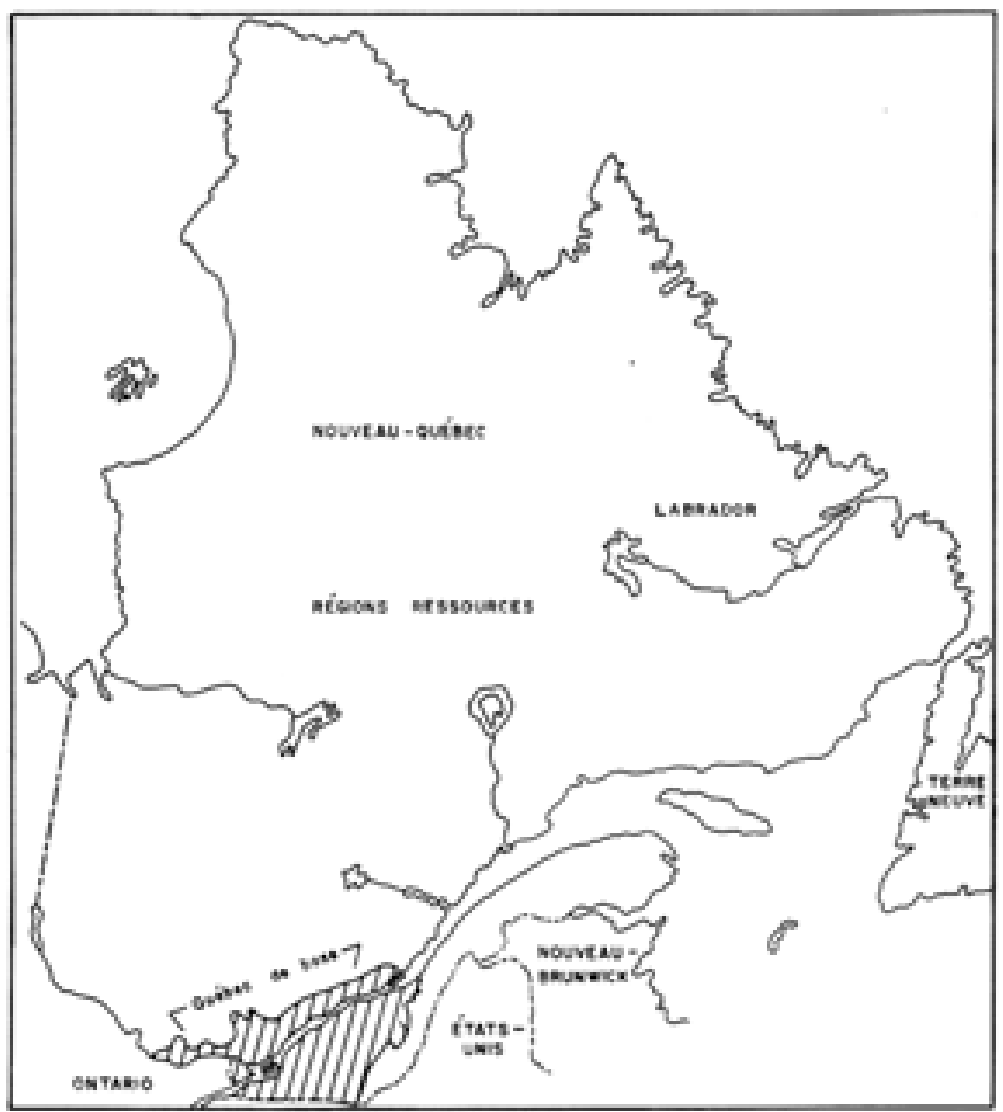

Source : OPDQ, 1973.

Par ailleurs, en 1982 sur la scène fédérale, le principe constitutionnel de l'égalité des chances économiques entre les régions, avait acquis le statut de droit économique fondamental (Axworthy, 1990). Par ce levier constitutionnel voué à la réduction des écarts économiques existants, le législateur voulait permettre ainsi l'établissement d'une dynamique sociale créatrice au sein du pays. Les régions du Nord du Québec étaient déjà à cette époque identifiées comme étant aux prises avec de graves problèmes découlant des disparités dans le développement économique. À cet égard, le gouvernement du Canada désirait empêcher que les collectivités régionales les plus 
fortes n'usent de leur supériorité pour créer des conditions économiques, sociales et institutionnelles telles que les régions les plus faibles ne disposent pas de chances égales. La garantie constitutionnelle qu'une telle situation de déséquilibre ne puisse se produire fit l'objet des engagements et des garanties de l'article 36. (1).

L'article 15. (1) venait renforcer le droit précédemment énoncé. Par celui-ci, les gouvernements étaient constitutionnellement obligés d'élaborer et d'adopter des lois, des politiques et des programmes qui satisfassent expressément à la réduction de l'inégalité des chances entre les personnes.

Toutes les provinces, sauf le Québec, ont adhéré et ont mis en pratique cette règle universellement éprouvée. À partir de 1982, la Constitution canadienne, au titre de contrat social ou de «convention collective » fondamentale, allait en direction inverse de celle résolument empruntée par le gouvernement du Québec depuis 1970. La Constitution préconisait l'inclusion. Elle obligeait à l'égalité réelle des chances économiques entre les citoyens d'une même collectivité et entre ceux des différentes régions. À l'instar des pays démocratiques, plutôt que la ségrégation en fonction de la région d'appartenance, elle consacrait l'égalité comme moteur principal du développement de l'ensemble de la société.

Seul de son côté, fait sans équivalent en Amérique du Nord et en Europe, le gouvernement québécois maintenait le cap sur son obsession : développer seulement une partie privilégiée de la société québécoise, en supposant d'éventuelles retombées, découlant de son rayonnement sur les autres régions. Rendu bien gras, bien dodu et bien majoritaire, l'ogre montréalais accepterait-il d'être mis au régime ou de partager les bénéfices escomptés pour appuyer plus tard à son tour, le développement social et économique des « régions ressources »? Trente années plus tard, force est de constater que de toute évidence la réponse est non! Après s'être délecté de la jeunesse et de la richesse des «régions ressources », il dominerait 
encore davantage l'Assemblée nationale, le gouvernement et, éventuellement, la haute administration publique. Aussi, il ignorerait les règles constitutionnelles fondamentales. Muni d'une parfaite domination des institutions, il continuerait à laisser sévir les conditions d'inégalités qui avaient créé sa seule croissance au plan social et économique.

\section{La réaction devant la connaissance des faits}

Retour à la table des matières

En 1986, d'importantes découvertes scientifiques décrivaient enfin clairement le processus ainsi que les causes du sous-développement constaté au Québec. Les travaux de recherche de Charles Côté - résumés dans le mémoire qu'il produisit pour le Conseil des affaires sociales et de la famille - sont alors portés à l'attention de la Commission sur l'avenir des municipalités. L'erreur québécoise avait porté ses fruits, aussi mesurables, qu'illégitimes et inconstitutionnels.

Ces découvertes cruciales pour l'avenir devaient impérativement trouver suite et être rendues publiques, de l'avis même de Jacques Parizeau, Président de cette commission. Cette sommité du monde universitaire de l'époque, concepteur influent des mécanismes de l'État québécois moderne dans les années 1970, confirma la pertinence des constats, la justesse de l'analyse des causes et l'étendue des dégâts déjà engendrés dans la société. Chacun pouvait, dès lors, comprendre l'ampleur, l'importance et l'urgence du coup de barre à donner.

Contre toute attente cependant, les travaux et constats de Côté ne furent jamais rendus publics. Plutôt que de divulguer intégralement ses travaux, on produisit un ouvrage de propagande intitulé Deux Québec dans un - Rapport sur le développement social et démo- 
graphique, l'une des bibles actuelles de l'action des CRCD, CLD et autres créatures ... La paternité de l'ouvrage était revendiquée notamment par Rémi Trudel ${ }^{20}$. Ce Polar péquiste de 150 pages ne divulguait aucun des constats scientifiques évoqués par Monsieur Parizeau. Il ne motivait aucune mesure correctrice d'État. Du travail initial du scientifique Côté, avait curieusement disparu toute référence à la persistance des niveaux de non-emploi comme facteur explicatif intermédiaire entre le mode de répartition des dépenses publiques et le déplacement démographique des populations des régions étiquetées "ressources», vers la région du GrandMontréal. L'argumentation simpliste et dépouillée s'y limitait aux seuls effets du processus sur la migration et le sous-développement social des populations, sans aucune allusion aux causes. Tout était présenté de manière à disculper nos Institutions et à les rendre étrangères au processus de création de notre sous-développement régional. Ainsi, le gouvernement condamnait les régions injustement et illégalement étiquetées « ressources », à aller rejoindre, en matière de sous-développement, le niveau des collectivités amérindiennes régionales. La création et le maintien des disparités régionales dans les niveaux d'emploi accentueraient la création des divers maux que chacune des collectivités, sans distinction quant à la qualité du sang premier, connait aujourd'hui.

Ainsi,

- exit l'ensemble des constats largement accrédités et la problématique réelle du sous-développement;

- exit les explications;

20 L'autre auteur éventuel de cette « œuvre » était Yvon Leclerc, actuel président de l'association des CLD. C'est ce dernier qui apparaît au dos de l'ouvrage. 
- exit les faits vérifiables et généralisables expliquant la fermeture en douce des « régions ressources »;

- exit les traces et les preuves de la catastrophe humaine et économique ainsi programmée.

À sa place, au profit de la collectivité du Grand-Montréal, tel que préconisé en 1973, le gouvernement a sans cesse continué à spécialiser les différentes parties du territoire québécois. Il a préféré utiliser le faux problème de l'importance quantitative de la population québécoise pour amener des régions vers leur fermeture en douce. Il n'a pas fait de l'occupation et de l'utilisation diversifiée des territoires régionaux, une priorité. Et il ne s'est nullement soucié de développement ${ }^{21}$.

En matière de développement démographique, contrairement à l'un de ses devoirs fondamentaux, le gouvernement québécois n'a posé aucun geste correctif ${ }^{22}$. Par sa politique de concentration de l'argent public et des emplois dans une seule région, par l'exode forcé des jeunes, la croissance démographique du Grand-Montréal s'est réalisée sur le dos des «régions ressources». Par sa politique, ce

21 La croissance donne une mesure quantitative de l'augmentation de la richesse d'une société. Le développement implique une croissance sans création d'inégalités et vise à fournir à tous les individus où qu'ils vivent, les mêmes chances d'épanouissement. Il s'agit donc d'un concept fondé sur le respect intégral de chaque être humain qui compose la société et sur le respect de toute la société et non d'une seule de ses parties. C'est justement ce que garantissent les articles 36 et 15 de la Constitution. Et c'est justement ce à quoi les gouvernements qui se succèdent depuis 30 ans à la barre de l'État québécois refusent d'adhérer.

22 Comment fonder une famille et procréer quand on doit s'exiler pour travailler, quand on travaille quelques mois par année, qu'on est loin de sa communauté, qu'on perd espoir et confiance envers son milieu naturel d'appartenance. 
gouvernement s'est contenté de favoriser la croissance d'une région, faisant très exactement comme si le reste de cet immense pays n'existait pas. Sauf en période électorale, par des paroles vides, ou dans de trop rares périodes de ras-le-bol populaires.

Pendant ce temps, en matière sociale, l'action gouvernementale québécoise de concentration massive de l'argent public créait ses ravages. Une part croissante des territoires ruraux et urbains n'était plus en mesure d'offrir des conditions de vie suffisantes pour attirer une population active composée de jeunes adultes ou de parents potentiels. Plus cette tendance observée depuis 1971 se maintiendrait, conformément à la volonté gouvernementale, plus les écarts et les inégalités entre individus ou communautés se maintiendraient ou augmenteraient. La politique sociale pratiquée ne visait nullement l'égalité des chances de chacun, afin qu'il se réalise pleinement dans un environnement sain où qu'il vive sur le territoire. Les gouvernements successifs ont plutôt considéré que de tels facteurs de développement auraient nui au développement prioritaire de Montréal. Les seuls projets qui justifieraient l'aide gouvernementale aux « régions ressources » continueraient donc à être prioritairement ceux liés à l'extraction de la ressource et au pire, à leur première transformation ou encore au maintien d'une politique de bien-être, telle que l'avait décrite Gérald Fortin en 1971.

"Ainsi s'inscrit très souvent, dans les programmes et les politiques de développement régional, une ambiguité qui, sans doute rend ces programmes rentables au point de vue électoral, mais les rend presque inefficaces. Il s'agit de l'ambiguïté entre programme de bien-être et programme de développement. Le programme de bien-être doit à court terme soulager sur place la misère ou la pauvreté. Comme tel, il ne s'attaque pas aux sources ou aux causes de la pauvreté, mais veut en atténuer les effets. Normalement de tels programmes devraient chercher à réhabiliter les individus ou les groupes soumis à la pauvreté, mais ceci supposerait que les programmes de bien-être soient coordonnés avec les programmes de développement; ce qui en pratique n'existe 
pas actuellement. Ainsi pour efficaces que soient, à court terme, les programmes de bien-être, ils peuvent devenir très dommageables à moyen terme. En diminuant les manifestations de la pauvreté, ils ne s'attaquent pas aux causes réelles de cette pauvreté, de sorte que la situation globale s'en va lentement vers une impasse complète » (Fortin, 1971).

Le gouvernement n'a donc pas voulu voir la répartition de l'argent public pour le développement, comme un investissement. Pourtant, avec la part qu'elles représentent dans l'économie de la société, les dépenses publiques font, à elles seules, la différence entre progrès et stagnation, entre enrichissement et appauvrissement, entre développement et dépendance, entre peu d'emplois et plus d'emplois.

Face à ces faits, comment n'a-t-on pas compris qu'avant de concéder l'Approche commune, il y avait énormément de remises en question et de choses à régler dans cette province dont les amérindiens, quoiqu'ils en pensent, font partie intégrante et égale. Il nous faudrait impérativement exiger du gouvernement qu'il définisse clairement et sans équivoque l'identité de la société et du territoire auxquels il fait référence lorsque devant nous, il discourt sur la société québécoise sur le Québec moderne, le Québec de demain, le modèle québécois. En d'autres mots: «c'est qui » la société québécoise ? Et géographiquement, quelle direction devonsnous emprunter pour lui rendre visite?

\section{Les droits des autochtones amérindiens}

Retour à la table des matières

En août 1969, pendant que les tribunaux étudiaient l'affaire des Amérindiens Nishga de la Colombie-Britannique, le Premier ministre canadien avait déclaré «Nous ne pouvons reconnaître les droits des autochtones, car aucune société ne saurait être édifiée sur des 
hypothèses historiques " (voir à ce sujet les Débats de la Chambre des communes, novembre 1981). Des hypothèses !

En novembre 1982, dans l'Ouest du Canada, le débat autour des revendications des Autochtones amérindiens faisait toujours rage. En matière constitutionnelle, à la Chambre des communes, sous la pression des députés de l'Ouest du Canada, cela se traduisait par le renforcement de la cause des autochtones. Le moyen retenu alors par le législateur a consisté à inclure explicitement leur réalité dans la future Constitution canadienne, l'article 35. Ce dernier porterait sur les droits des peuples autochtones du Canada, mais dans une optique de préservation de la vigueur et de la diversité du patrimoine canadien ${ }^{23}$. Par la combinaison des articles 25 et 35 , le législateur du Canada comptait éviter toute identification entre une collectivité autochtone et une forme quelconque de gouvernement en particulier (Trudeau, 1990).

Dans un pays nouveau dont les principes étaient dorénavant fondés sur la primauté du droit et du citoyen, le gouvernement espérait que la pensée nationaliste indépendantiste amérindienne ou autre ne tendrait pas à identifier l'intérêt des collectivités avec un territoire dit ancestral. Il n'était pas souhaitable de continuer à traiter les amérindiens en leur accordant un statut particulier. Dans le contexte multiculturel canadien, le fait d'accorder des statuts particuliers à des collectivités qui se définissaient comme «premières », équivalait à une reconnaissance que les Amérindiens avaient raison de se considérer comme une race à part. Le Parlement canadien ne voyait pas comment on pouvait fonder une société ouverte sur la base de l'ethnocentrisme ou de cette tendance à valoriser,

23 Voir à ce sujet le témoignage d'un témoin et concepteur incontournable de cette période : Pierre Elliott Trudeau. 
avant tout, son groupe social d'appartenance. Permettre une telle affirmation de la primauté des ethnies impliquait directement qu'un jour, tous auraient à vivre ensemble sans communiquer entre eux, sauf au niveau officiel de l'État. Cela impliquait aussi qu'il s'introduirait divers nationalismes par lesquels, en fonction de la race ou de l'ethnie, serait désormais assigné aux citoyens le rang de première, deuxième ou troisième classe ${ }^{24}$.

Le défi était donc d'une toute autre nature. Encadrés par une Charte constitutionnelle qui garantissait l'égalité sans discrimination, tous les systèmes de valeurs de toutes les communautés - dans un esprit d'ouverture, de fraternité et de solidarité - devaient sainement interagir entre eux pour susciter le bien de tous. Ils ne devaient pas soumettre les uns à la primauté des droits des autres.

Alors qu'à la Chambre des communes les députés cherchaient à estimer les impacts possibles d'une protection constitutionnelle accrue envers les Amérindiens, le gouvernement canadien avait déclaré « il incombera aux tribunaux de faire l'interprétation juridique des faits ». Les Canadiens s'ouvraient à l'importance de planifier l'édification de la société et son développement, sur la base des faits de la réalité plutôt que sur la base des hypothèses. Aussi, au cas où les tribunaux prendraient une orientation allant à l'encontre de la volonté du Parlement fédéral, était évoqué le recours à la «formule d'amendement qui permettra au Parlement et

24 Or le nationalisme québécois a déjà créé des citoyens qui selon leur région d'appartenance (région ressource) sont traités en citoyens de deuxième classe. Et bientôt, l'Approche commune créera d'autres citoyens qui en raison de la reconnaissance intrinsèque qu'ils sont bien une race à part, deviendront des citoyens de première classe. En terme de qualité effective dans la reconnaissance que fait le gouvernement de la qualité de leurs droits à se développer, ils iront rejoindre la grande collectivité de la zone montréalaise laissant derrière les citoyens « ressources ». 
aux assemblées législatives des Provinces d'apporter certains redressements " (Débats de la Chambre des communes, novembre 1981).

Par après, vers 1986, la force du lobby des Premières nations montait en puissance ${ }^{25}$. Le gouvernement adopta alors une nouvelle politique. Se basant sur les jugements rendus par les tribunaux canadiens en matière d'interprétation de l'article 35.(1), toute revendication serait évaluée selon les critères de faits suivants :

1. Le fait de la continuité depuis des temps immémoriaux dans l'organisation sociale du groupe qui revendique droit et titre;

2. La continuité d'occupation du territoire depuis des temps immémoriaux;

3. L'exclusivité d'occupation du territoire;

4. La continuité de la pratique d'activités traditionnelles sur le territoire;

5. La non extinction des droits ancestraux (Dupuis, 1989).

En 1988, dans le cadre de sa Politique sur les revendications territoriales globales, le gouvernement fédéral acceptait de négocier avec quatre collectivités innues. Dotées «d'experts" à leur solde, les chefs firent accepter par leurs vis-à-vis fonctionnaires leur perception quant à leurs revendications territoriales globales. Ils firent accepter qu'elles reposent sur l'affirmation d'un titre autochtone continu sur les terres qu'elles alléguaient avoir occupé ainsi que sur

25 « En effet, afin de mieux exprimer leur prétention à un droit à l'autodétermination*, les Amérindiens du Canada s'appellent désormais les «Premières Nations » » (Flanagan, 2002). 
les ressources naturelles qui s'y trouvaient. Tel que défini par la Cour suprême, ce titre était censé reposer fondamentalement sur la continuité d'occupation.

En l'an 1991, le chef du conseil de bande de Mashteuiatsh déclarait que les revendications territoriales des Montagnais du Lac SaintJean - les futurs Innus - représentaient approximativement le territoire de la réserve à castors Roberval située dans le bassin de la rivière Ashuspmushuan $\left(250 \mathrm{~km}^{2}\right)$.

À la même époque, du coté gouvernemental, à propos des revendications autochtones amérindiennes au Québec, l'influent Lucien Bouchard déclarait :

"Ce n'est pas vrai qu'il y aura la souveraineté dans la souveraineté, à la manière des poupées russe. [...] Le Québec est un territoire dont il faut protéger l'intégrité. Il faut qu'il y ait un gouvernement, un Etat légitime qui exerce l'autorité sur ce territoire. Après, on peut faire des arrangements! Depuis 1985, le Parti Québécois utilise l'expression "autonomie au sein du Québec ». Je pense qu'il y a là, inscrite en filigrane, l'idée qu'il n'y aura d'autre souveraineté que celle dont le Québec sera dépositaire »(Bouchard, 1991).

En 1993, loin de s'achever, la politique négligente et à courte vue appliquée par le Parti conservateur du Canada, prit même de l'ampleur grâce aux libéraux dirigés par Jean Chrétien. En effet, le plan d'action libéral du Canada - le Livre rouge du Parti libéral s'engageait à reconnaître aux Amérindiens le droit inhérent à l'autonomie gouvernementale. Les Canadiens assistaient ainsi, sans trop s'en rendre compte, à la poursuite d'une dérive par rapport à l'esprit de la Constitution du pays.

Par l'outil des droits à l'égalité sans discrimination, la Constitution avait en vain ouvert la voie à la volonté fondamentale que les Amérindiens puissent intégrer la société canadienne, en conservant leurs valeurs, leurs coutumes et leurs traditions. 
De l'intégration dans l'égalité à l'ethnocentrisme institutionnel, il n'y avait qu'un pas à franchir. Et il a été franchi ! C'est ce que, confirma par l'Approche commune, le gouvernement de la société québécoise, sur le dos des « régions ressources ».

En juillet 2000, le Canada et le Québec faisaient connaître la conclusion entre les gouvernements québécois, fédéral et les leaders amérindiens d'une entente de principe devant servir d'assise à la signature d'un traité : l'Approche commune.

- Elle était basée sur des hypothèses historiques touchant notamment la continuité d'occupation plutôt que sur des faits de nature à étayer la preuve, telle que déterminée par la Cour suprême du Canada;

- Elle conférait aux collectivités innues les instruments d'un État : droit de faire leur Constitution, pouvoir législatif et exécutif, territoire possédé en propre, contrôle effectif sur le territoire limitrophe, reconnaissance de droits constitutionnellement reconnus sur le territoire limitrophe.

- Elle définissait les éléments-clés, tels la quantité des terres, les implications financières, le partage des recettes provenant de l'exploitation des ressources naturelles et les engagements à l'autonomie gouvernementale.

Il restait à trouver plus tard une formule acceptable concernant la reconnaissance et la certitude des droits et titres autochtones sur les terres, sur le droit inhérent et sur la nature générale du droit de légiférer.

Deux ans plus tard, en juin 2002, il apparaissait que les nouvelles revendications territoriales des Innus du Lac Saint-Jean - enfin connues, à cause de la pression exercée par quelques citoyens inquiets et éveillés - montraient, comparées aux revendications de 1991, des signes d'obésité. Elles étaient composées d'un «Innu assi » (titre aborigène sur des parcelles de terre) totalisant 
$3300 \mathrm{~km}^{2}$ avec les parcs et sites patrimoniaux. À cela s'ajoutait un second ordre de titre, un «Nitassinan ${ }^{26}$ recouvrant l'essentiel de la région du Saguenay-Lac-Saint-Jean. Selon l'article 17.2.3 de l'Approche commune, le titre aborigène sur ces territoires serait réexaminé - à la hausse mais jamais à la baisse - périodiquement. Il était confirmé que l'entente créerait des gouvernements innus. Nos Élus, qui avaient été, sciemment ou non, totalement absents des pourparlers, étaient notamment invités par les leaders amérindiens à faire preuve de courage : sans doute pour abonder dans le sens des parties gouvernementale et Innue.

En septembre 2002, alors que devant la Cour suprême du Canada en 1997, les aînés de 71 tribus (maisons) de la Colombie-Britannique avaient établi par eux-mêmes, la preuve de leur occupation ancestrale originelle, au moyen des récits oraux intergénérationnels, le Chef Moar de Mashteuiatsh déclarait que "le traité et les principes en voie d'être mis de l'avant, ... doivent être placés audessus des opinions, partis pris et divergences de vues des historiens ». Ceux à la solde des Innus « ont une toute autre perception de notre nation » (Innu).

\section{Des jugements à bien lire ...}

Puisque les promoteurs de l'Approche commune l'évoquent si souvent en lui faisant dire à peu près n'importe quoi, sachons que dans la cause Delgamuukw contre le gouvernement de la Colombie-Britannique, en 1997, il apparaîtrait que ce sont les Indiens eux-mêmes et non des historiens à leur solde qui ont

26 On notera que le texte principal de l'Approche commune n'utilise qu'une toponymie "originale» innue pour désigner les territoires en cause. Il devient ainsi très difficile pour tout citoyen de reconnaître que c'est de toute sa région qu'on parle quand on utilise le terme Nitassinan, jusqu'à tout récemment parfaitement inconnu de la majorité. 
témoigné devant la Cour. Ils ont livré une preuve de leur occupation ancestrale des territoires revendiqués. À cette fin, ils avaient livré dans leur langue, les dits récits oraux, montrant le lien entre les coutumes, valeurs et traditions et le territoire tribal totalisant 58,000 kilomètres carrés.

Cette preuve, dans le cadre de l'article 35.(1), repose sur la transmission verbale (récits oraux) intergénérationnelle du lien sacré entre le territoire et le groupe (maison). Les aînés ont témoigné dans leur langue originelle et il fallut des interprètes pour permettre à la Cour d'en apprécier le contenu. Les chefs héréditaires ont également témoigné. Voilà un indice très important afin de déterminer la profondeur de «l'amérindianité » de ceux qui, là-bas, réclament droits et titres.

Le résultat du jugement final de la Cour fut simplement de déclarer que la Cour suprême de la Colombie-Britannique aurait dî accepter à titre de preuve, les témoignages oraux transmis de génération en génération et concernant des valeurs coutumes et traditions qui établissaient un lien spécial avec un territoire délimité. La Cour suprême du Canada a recommandé au gouvernement soit de recommencer un autre procès, soit de tenter de concilier.

Aussi, la Cour suprême laisse comprendre que les territoires de trappe de fourrures pour fin de commerce avec les Européens, ne peuvent faire partie des revendications territoriales. Le commerce n'est pas une valeur, une coutume et une tradition typiquement amérindienne. Le commerce des fourrures fut induit avec l'arrivée des Européens.

Quant à l'interprétation gouvernementale à l'effet que la Cour suprême aurait déclaré que les Indiens sont les premiers habitants du Canada, il n'est nullement nécessaire aux contribuables canadiens de payer une Cour suprême pour le savoir. Cela démontre bien la faiblesse de la position gouvernementale et l'infantilisation qu'il fait des citoyens du Saguenay-Lac-Saint-Jean et de la Côte-Nord.

Dans le cadre de ce procès, concernant la conciliation, jamais la Cour n'a conseillé à toutes les provinces d'en faire autant. Chaque cas est particulier. À la grandeur du Canada, 604 bandes amérindiennes constituent autant de cas particuliers qui commandent autant de jugements particuliers. 
L'affirmation du titre autochtone continu sur lequel repose l'entente cadre de 1988 précédemment évoquée, reposerait donc ici sur une vue d'historiens qui pourrait être divergente, plutôt que sur des faits. On se baserait donc sur une hypothèse historique comme le confirme le Préambule de l'Approche commune cité précédemment.

Devant l'ampleur et l'importance des constats qui contredisent les thèses des Innus quant à leur occupation ancestrale du territoire de cette région, le Chef Moar de Mashteuiatsh, évoquait la possibilité d'une «crise sociale». Un commentateur paternaliste régional de l'actualité écrivait: "nos amérindiens méritent un meilleur sort» (Bourdon, 2002). En quelque sorte, il invitait la population régionale à substituer aux principes reposant sur la primauté du Droit un droit accommodant taillé sur mesure. Bref, un droit interprété et établi de manière politicienne et partisane à la faveur des Amérindiens du Lac Saint-Jean. Il prenait cependant bien soin de ne pas étayer la validité constitutionnelle de ses positions.

De son côté, le député provincial de Chicoutimi tentait de justifier l'action gouvernementale, faisant valoir que des Amérindiens, sans doute quelque part dans l'Ouest canadien, avaient remporté des causes devant les tribunaux. Par voie de conséquence, la situation commanderait donc maintenant aux citoyens de cette région, tels des moutons de Saint Jean-Baptiste apeurés, d'accepter béatement les avantages concédées sans contrepartie aucune en matière de droits ancestraux et de titres sur le territoire (Parizeau, 2002).

Le compétent «Élu chicoutimien » ignorait peut-être que d'autres jugements existent qui confirment les droits à l'égalité, à la liberté et à la justification, par le gouvernement, de toute politique différentielle de traitement à la faveur des uns alors que les autres éprouvent les mêmes besoins. En bon élu, il devait certainement savoir que, pour le rattrapage économique et social de la collectivité qu'il a devoir de défendre sur la base de ses droits réels et fondamentaux, 
des « ententes » devraient aussi être négociées avec les autochtones canadiens français de la région. Plus fidèle et solidaire envers son parti politique qu'envers sa communauté citoyenne territoriale, il est resté muet sur ce dernier énoncé. Définitivement, nos prochains élus ne devraient plus jamais être des avocats qui ignorent l'importance d'une constitution pour qui veut diriger un Pays qui serait autre chose qu'une tyrannie des plus effrontés!

Enfin, en novembre 2002, l'ex-militant pour le respect des droits de l'homme, auteur présumé de l'évangile péquiste «Deux Québec dans un », ministre délégué à la Population et aux Affaires autochtones, responsable des régions et du développement du Nord du Québec, du nom de Rémy Trudel, au sortir d'une autre activité proInnu, déclarait «opter pour la voie de l'humanisme»! ? Cherchez l'erreur! 


\section{Chapitre VI}

\section{L'équité n'est pas l'égalité}

$\underline{\text { Retour à la table des matières }}$

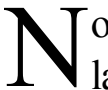

ous avons constaté, je l'espère, que l'article 15 est le pivot de

a Charte des droits et libertés. La discrimination dont cette clause fait état se rattache normalement à des groupes minoritaires qui n'ont pas assez de pouvoir politique pour jouir d'un égal traitement de la loi. De ces groupes minoritaires dans la société canadienne s'entend notamment des Indiens du Canada.

Nous avons également compris, du moins je l'espère, que deux groupes dans la société, ont réussi à renverser en leur faveur, l'ordre constitutionnel établi, qui (ailleurs qu'au Québec) garantit l'exercice des droits fondamentaux. Un premier groupe, la collectivité humaine du Grand-Montréal est déjà dominante à tous points de vue. Un second groupe, les Amérindiens, domineront bientôt peut-être pas seulement le Québec mais le Canada en entier.

La faiblesse, voire même l'incapacité chronique des Assemblées de nos représentants élus à gouverner selon la Constitution, les programmes de partis politiques et les discours électoralistes auront permis aux Indiens d'exercer une influence devenue, au fil des années, complètement démesurée et même prépondérante, sur le gouvernement. L'ordre établi par la Constitution et la Charte est en voie de sombrer dans le désordre. La question est moins de savoir où s'arrêteront les revendications des Amérindiens que de savoir qui mettra démocratiquement mais résolument un frein à leur 
redoutable et insatiable appétit. Un appétit nourri par l'obsession qu'ils sont les premières nations et qu'à ce titre, ils doivent être confirmés dans leur droit de s'auto-exclure mais toutefois aux frais des méchants autochtones de souche européenne que nous sommes. $\mathrm{Au}$ rythme actuel, à quand les poursuites contre ceux qui osent encore exprimer démocratiquement leurs désaccords?

Nous sommes aux prises avec un gouvernement qui gère la société en se fondant sur diverses hypothèses. Nous devons subir quotidiennement les effets néfastes de sa politique de génération des inégalités entre les régions. À sa place, au titre de citoyens responsables, nous devons donc faire preuve de la plus grande prudence. Dans le contexte de l'Approche commune, encore à titre de citoyens responsables, nous nous devons de considérer qu'une société dont les principes sont fondés sur la primauté du droit peut accorder le poids qu'il faut au point de vue des Innus. Cependant, il nous faut considérer qu'il s'agit d'une minorité composée d'individus qui, comme tous les autres, possèdent les mêmes droits fondamentaux que les autres individus qui composent les majorités, $n i$ plus, ni moins.

Toutefois, au contraire du gouvernement, nous n'avons nullement à nous excuser envers les Innus et à tenter d'acheter la paix. Nous devons veiller à ce qu'il n'y ait pas entorse à l'organisation juridique et constitutionnelle de notre société civile inclusive. Nous devons constamment nous souvenir qu'au cœur de notre organisation en société, figure la liberté par l'égalité des chances que procure la répartition équitable de la richesse collective et des emplois.

Les maux qui ici découlent du sous-emploi - engendré par l'action gouvernementale qui crée l'inégalité - sévissent, sous diverses formes, autant dans la collectivité autochtone amérindienne du Lac Saint-Jean que dans la collectivité autochtone canadienne française régionale. Ils sont aussi inacceptables pour l'une que pour l'autre. 
Le drame de l'Amérindien qui souffre des effets du sous-emploi et de la pauvreté est tout aussi inacceptable que le drame du Canadien français d'ici. Les drames humains qui se cachent derrière l'accroissement continu des taux de suicide d'une collectivité sont autant intolérables dans l'autre. La tragique réalité du jeune Amérindien qui, dans sa collectivité, est désœuvré et désespéré est aussi poignante que la tragédie humaine du jeune Canadien français qui, en désespoir de cause, se voit contraint de s'exiler vers la grande région de Montréal pour trouver enfin un emploi plutôt que le chômage et la solitude dans sa communauté d'appartenance.

La puissance du lobby amérindien canadien et la faiblesse du gouvernement de la société québécoise - la puissance du premier n'ayant de force que la faiblesse du second - ne peuvent justifier, envers nos régions, une situation où on imposera un traité dont la base est non fondée en droit.

Dans cette affaire d'Approche commune, il ne s'agit pas de reconnaître des droits au lobby ou à la Nation innue en tant que regroupement de bandes au sens large du terme. Ici et maintenant, nous avons affaire plutôt au groupe ou à la bande autobaptisée Innu du Lac-Saint-Jean et de la Côte-Nord. Par laxisme ou largeur d'esprit congénitale, il n'y a pas lieu de reconnaître des droits spécifiques au groupe innu, alors que sur le fond, leur droit à cet égard n'est pas solidement démontré.

Il faut, d'autre part, souligner que la prolifération sur le territoire d'États nés de l'ethnocentrisme amorcera la fin des régions étiquetées « ressources » et par conséquent le démembrement progressif du territoire québécois lui-même. Cela est d'autant plus inacceptable que nous savons que l'article 35. (1) de la loi constitutionnelle de 1982 se veut avant tout une réponse pan canadienne à une problématique amérindienne tout à fait spécifique à l'Ouest canadien, en particulier à la Colombie-Britannique. Qu'on se le dise, l'aura juridique autour de la problématique spécifique des Innus du 
Lac-Saint-Jean et des autres collectivités innues, en est une importée de l'Ouest du Canada.

Dans le cadre de l'article 15, chaque citoyen peut intégrer la collectivité régionale tout en conservant sa langue, sa culture et ses traditions. La communauté amérindienne désire-t-elle agrandir son aire de vie urbaine? Aucune loi civile ordinaire ne l'en empêche. Pour l'expression de sa culture, de certaines valeurs ou traditions, désire-t-elle absolument la "réserve à castors Roberval située dans le bassin de la rivière Ashuapmushuan $"{ }^{27}$ ? Il est pensable que l'autre collectivité n'y voit pas de réels inconvénients et qu'un simple décret gouvernemental satisfasse à sa garantie d'utilisation. Comme tous les autres, un citoyen amérindien désire-t-il suivre un programme de formation, désire-t-il un emploi, une maison? Désire-t-il habiter la ville ou son village natal ? Désire-t-il vivre en marge de la société ou est-il décidé à demander l'aide communautaire? Lui refuse-t-on un emploi, un service ou un logement? Il peut faire appel à deux Commissions des droits et libertés. Selon son revenu annuel, il peut demander aussi de l'aide juridique.

Mise à part la théorie du retour en arrière, toutes les possibilités et les mécanismes sont présents, disponibles et à la portée de chacun et de tous, même de ceux qui veulent s'en distinguer par traité !

27 Dans son édition du 29 août 1991, le journal Le Quotidien rapportait dans un article titré «Kurtness sourit à la nouvelle commission » : "Selon Rémy Kurtness, les revendications territoriales des Montagnais du Lac Saint-Jean représentent approximativement le territoire de la réserve à castors Roberval situé dans le bassin de la rivière Ashuapmushuan ". La Commission dont il était question était la Commission royale d'enquête sur les peuples autochtones. Le lecteur apprendra que la Cour suprême du Canada a articulé la preuve pour la reconnaissance des droits existants ancestraux sur les recommandations de cette Commission (document tiré du Fond de recherche de Russel Bouchard, historien). 
N'en déplaise à ce gouvernement, tels sont les éléments de l'âme et de la lettre du contrat social fondamental redéfini et signé en 1982. Il ne peut pas préconiser un genre d'égalité pour la grande collectivité montréalaise, une autre pour les Innus et six autres pour chacune de ces « régions ressources ».

Les promoteurs gouvernementaux de l'Approche commune mettent de l'avant l'idée que nous devons être équitables envers les Innus. Il ne faut cependant pas confondre équité avec égalité. Alors que l'équité est arbitrable et qu'elle relève d'une opinion à l'endroit d'une collectivité par comparaison avec l'autre, l'égalité est scientifiquement identifiable, vérifiable, mesurable et comparable. Alors que la première peut s'exercer de façon volontaire ou par la contrainte, la seconde (sauf au Québec) a atteint un caractère étendu, obligatoire, sans discrimination et non négociable. Quelques étages plus hauts que l'équité, la Constitution canadienne oblige à l'égalité. Alors que le sous-développement et ses effets sévissent dans les deux collectivités régionales, il s'agit de ne pas agir encore une fois en totale négation de la réalité des inégalités. Dans la réalité, l'enjeu consiste à commencer par être égaux. Toutes races confondues, en matière d'égalité, face à la grande région élue, nous avons tous un énorme fossé à combler.

S'agissant de simplement concilier les intérêts ou de réclamer une équité, encore faut-il préalablement répondre adéquatement à certaines questions de base :

- Face à la grande collectivité montréalaise et face aux Amérindiens innus, sur la base des faits de la réalité, devrions-nous conclure que nous sommes riches ou appauvris, égaux ou inégaux, socialement et économiquement vigoureux ou moribonds?

- À l'égard des perceptions véhiculées sur notre situation par rapport à l'autre, par quels intérêts ont-elles été forgées? 
- À coup de sommes colossales provenant de l'argent public, quelle est la valeur réelle du discours employé par le gouvernement et les promoteurs afin de nous forger collectivement une perception positive de notre situation et une autre perception, paternaliste, émotive et dramatique de la situation des Innus ${ }^{28}$ ?

- Comment se fait-il que des commentateurs induisent l'idée que nous devrions faire des Innus, des pupilles exclusifs de l'État canadien renouvelé ?

- Serait-il possible qu'historiquement les Innus aient agi de manière à ériger autour d'eux, les murs de leur propre ghetto ?

- Est-il possible que la solution véritable à leurs problèmes ne réside pas dans l'Approche commune mais dans un simple recours à la fraternité et à la solidarité citoyenne ?

- La société civile canadienne française régionale a-t-elle déjà refusé aux Innus leur intégration dans le processus de la création de redistribution et de consommation de la richesse collectivement créée?

- L'humanisme nébuleux prôné par la faction gouvernementale commande-t-il de partager ce que collectivement nous n'avons pas ? Commanderait-il plutôt de veiller à ce que la Constitution du pays soit appliquée sans discrimination à chaque citoyen et à son groupe d'appartenance ?

$28 \mathrm{Si}$ les considérations humanitaires importent tant à nos gouvernements, comment s'expliquer que les Innus du Labrador qui vivent des situations communautaires autrement dramatiques que celles de nos régions ne se soient pas vu offrir en priorité une entente similaire à l'Approche commune? 
Tel que la loi fondamentale de ce pays le stipule et l'exige, pourrions-nous dans un geste éclairé, devenir d'abord formellement égaux ? Pour la suite des choses, il est pensable que deux collectivités qui ont réussi à combler les écarts de développement entre elles et la grande région la plus développée, n'aient plus beaucoup matière à discuter d'équité mais plutôt de lendemains fraternellement meilleurs. Alors que les deux collectivités canadiennes autochtones de notre région ont sous les yeux la preuve des effets néfastes des inégalités, il apparaît que la plus petite disposera d'un règlement politique qui la propulsera vers la réalisation de son droit à l'égalité. Pour la plus grande, les mécanismes nécessaires au développement ne seront nullement remis en fonction : elle restera donc exclue du traitement distinct légalisé par le traité.

Devant ces faits et dans ce contexte, il apparaît que nous sommes en devoir d'indiquer à nos représentants élus qu'en regard du droit entourant la Constitution, ils ont laissé le gouvernement procéder à une mauvaise identification du groupe qui devrait bénéficier de l'effet améliorateur du nouveau programme que fondera 1'Approche commune.

Qu'on se le tienne pour dit : il est constitutionnellement impossible que les tribunaux aient dicté aux Canadiens français et aux Canadiens anglais de quelque province que ce soit, de faire des Innus et des Amérindiens une, dix, cent ou six cents Nations politiquement distinctes et tournées vers l'autodétermination dans la Nation canadienne ou québécoise.

Cela impliquerait que sans consultation nationale, les canadiens et canadiennes, satisfassent les visées ethnocentristes tant amérindiennes que québécoises. Il serait désormais reconnu que le contrat social fondamental et la charte des droits fondamentaux des citoyens peuvent être subordonnés à une simple loi ou un simple traité. 
Par loi ou traité, une législature provinciale accorderait le droit à des groupes ou bandes amérindiennes, les outils et droits de promouvoir et de former autant de sociétés distinctes en plus des 10 provinces parties à la Constitution. On avantagerait ainsi une minorité qui, comme tant d'autres, possède une culture, une langue, des traditions et des intérêts divers - en l'identifiant comme unique et distincte des autres.

Par ses articles, la Constitution canadienne affirme haut et fort que les Amérindiens (innus) sont égaux. Elle affirme qu'ils peuvent s'intégrer à la société civile en conservant, comme le font des centaines d'autres communautés dans le Canada, leurs valeurs, leurs coutumes et leurs traditions. Il est ainsi affirmé que les individus, en lien avec leurs communautés et groupes d'appartenance, ne peuvent être traités différemment. Ils ne peuvent d'aucune manière être discriminés.

La Constitution n'affirme pas cependant que les Amérindiens innus n'ont pas le droit aussi de s'auto exclure, de s'enfermer dans des ghettos et de refuser de contribuer citoyennement à la société. Ils en ont entièrement le droit et c'est d'ailleurs ce que certains ont fait. Cependant, que ces derniers ne viennent pas ensuite nous «mettre sur le nez » à nous que "ça va mal à la shop »! Qu'avec le gouvernement, ils ne viennent pas nous dicter qu'il faut absolument qu'à même le patrimoine collectif composé de droits fondamentaux et de divers types de richesses, nous devions être équitables à leur endroit au point où il leur soit permis de devenir un État national développé en plein cœur d'une région sous-développée! Que leurs complices ne viennent pas exiger de nous que les libertés des citoyens canadiens innus, puisqu'elles existent déjà également pour tous, soient réinventées et améliorées par l'Approche commune à leur unique faveur, "gossées " à même les droits à l'égalité des Canadiens français. 
Attendre, supplier, pétitionner ou demander la conciliation sont des gestes insuffisants pour ne pas dire insignifiants. Nous ne sommes pas tombés de la dernière pluie. Comme cela est son habitude, c'est sur de tels terrains que ce gouvernement, encore une fois, nous espère et nous attend. C'est exactement sur le terrain de la perception collective émotive de nous-mêmes par rapport aux autres, qu'il tente de nous amener.

Même si nous sommes vingt ans en retard, force est de croire que collectivement, sans distinction quant à la région d'appartenance ou quant à la qualité du premier sang autochtone, fraternellement, les citoyens doivent aller vers la conquête d'une égalité unique. Ils doivent y parvenir par la recherche de l'égalité entre leur collectivité inclusive (canadienne française et amérindienne) et la collectivité qui occupe la grande zone montréalaise.

\section{Collectivement, vivre dignement ou disparaître}

$\underline{\text { Retour à la table des matières }}$

Dans le contexte de la violation, par le gouvernement, des droits à l'égalité sociale et des droits à l'égalité des chances économiques régionales des Canadiens français d'ici, l'action gouvernementale d'Approche commune - contrairement à l'esprit que les promoteurs tentent de véhiculer - n'est pas un dossier sectoriel ou conjoncturel. Elle n'a rien à voir avec un dossier du genre bout de route, casino, problème du lait. Elle ne peut surtout pas être l'aboutissement d'un vaste jeu de pressions (lobby) politiciennes. Visiblement, l'action gouvernementale dite d'Approche commune est la négociation de droits fondamentaux. Le gouvernement et tout individu peuvent négocier à peu près n'importe quoi sur le dos d'un autre qui n'est pas partie à la négociation, mais jamais les droits et les libertés fondamentales individuelles. Un tel geste ne peut être posé car nous savons maintenant que les droits et les 
libertés individuelles et collectives n'appartiennent pas à l'État ni au gouvernement. En dépit de cette règle incontournable, si le gouvernement s'entêtait quand même à procéder à la cession de nos droits, il devra alors faire ouvrir la convention collective citoyenne fondamentale et ce, avec les véritables maîtres souverains de ce pays, les citoyens. Il devra renégocier le contrat fondamental, la Constitution. Un point, c'est tout !

N'avons-nous pas notre «voyage» de cette gestion gouvernementale par hypothèses? Aux gestions basées sur des hypothèses sociales, économiques et historiques, allons-nous accepter d'ajouter, en plus la gestion reposant sur des hypothèses juridiques constitutionnelles? Dans un tel contexte et dans l'ordre démocratique naturel de l'avancement de la société, l'Approche commune est un « dossier » qui, purement et simplement, commande une étude d'impact citoyenne sur leurs droits fondamentaux garantis sans discrimination aucune. Non partisane, elle devrait reposer sur une information complète des droits et des libertés fondamentales de tous les citoyens. Si nos élus démontrent à l'évidence ne pas connaître leur Constitution, au moins les citoyens la comprendrontils mieux. De la sorte, pour assurer la survie de leur collectivité, ils pourront se gouverner en conséquence ! Dans le contexte des droits plus généraux aux diverses égalités des citoyens autochtones canadiens français que nous sommes, l'étude des impacts de l'Approche commune se révèle d'une importance extrême.

Dans tel contexte, cela signifie que tout élu serait sans délai tenu de faire preuve d'une extrême réserve, en l'absence d'un mandat issu du jugement éclairé des citoyens qu'il représente. Celui qui se livrerait à la promotion de l'action gouvernementale d'Approche commune, sans mandat de ses commettants, devrait pour son inconséquence être répudié sur le champ ! Vu la complexité du sujet et la portée du consentement qu'on nous enjoint d'accorder à l'aveuglette, aucun autre politicien (élu ou membre de l'exécutif) ne 
devrait se sentir mandaté pour quelque conciliation ou à quelque recherche d'équité que ce soit. En regard des droits fondamentaux de tous les citoyens d'ici, les questions et les problématiques fondamentales que soulève l'action gouvernementale sont graves :

- Qui sont-ils ces élus, représentants et fonctionnaires, pour se permettre par leurs agissements, de tripoter ainsi la Constitution?

- De quel droit ces individus qui, jusqu'à présent, se sont montrés si incompétents, ignares, partisans et serviles, peuvent-ils, de façon crédible, lancer le message que l'Approche commune est une nécessité ?

- De quel droit engageront-ils les citoyens dans un traité dont les clauses seront inscrites dans la loi fondamentale du pays pour l'éternité ?

Si pour la relocalisation d'une colonie de "grenouilles poilues » ${ }^{29}$ d'un ruisseau à un autre, le gouvernement est prêt à dépenser des millions de dollars pour étudier l'impact environnemental, ce même gouvernement devrait accourir afin de donner aux citoyens d'ici les ressources financières nécessaires pour étudier en profondeur l'impact sur la Nation du déplacement forcé des jeunes canadiens français de leur communauté d'appartenance vers la région du Grand-Montréal! Il devrait s'empresser de donner aux citoyens d'ici, les ressources qu'il faut pour étudier aussi l'impact sur la Nation d'accorder un traitement différentiel à la faveur des seuls Innus, alors que les Canadiens français d'ici, pour leur développement, ont les mêmes besoins.

29 Réfère à l'expression : « Gosseux de poils de grenouilles 》 lancée par Guy Chevrette en octobre 2000 en présence de médias pour ridiculiser les rares opposants d'alors à l'Approche commune. 
L'accomplissement de notre travail de citoyens responsables commande seulement que nous cessions de percevoir la Constitution canadienne comme un document au contenu inaccessible, inutile et étranger; il commande également que nous cessions de penser que l'usage des tribunaux est réservé aux autres plutôt qu'à nousmêmes! La Constitution n'est autre chose que la convention collective fondamentale entre les citoyens et le Gouvernement de leur Société. Elle n'est pas l'aboutissement de la volonté d'ordonner l'effort collectif des Lapons mais bien celui des Canadiens dont nous sommes encore!

Dans le contexte de la violation des droits fondamentaux, si un employeur avait, depuis 20 ans fait subir aux travailleurs et travailleuses le centième de ce que nous a collectivement fait notre gouvernement, il y a belle lurette que tous ces lésés seraient dehors dans la rue, pancarte à la main, scandant avec raison «SO-SO-SOSOLIDARITÉ ». Si les citoyens d'ici ne sont pas prêts à faire l'effort de comprendre à un degré minimal leur Constitution, à exiger son respect et à faire appel aux plus hauts tribunaux, il ne restera plus qu'à mourir cocus et contents.

Ne nous leurrons pas! Jamais le gouvernement n'aura le courage d'aller de lui-même dans la direction précédemment énoncée. Tout au plus, pourra-t-il en donner l'illusion ou mieux encore, nous envoyer quelques ministres pour jouer les préfets de discipline. Pis encore, sous le couvert d'informer justement, il fera fonder à même l'argent collectif - les fonds publics - un nouveau journal dont la secrète mission serait de propager la foi partisane. Dans ce contexte, la seule direction à emprunter est alors fort simple : elle consiste dans le recours réel aux tribunaux. Voilà d'ailleurs un geste qui aurait du être posé dès le lendemain de la publication en 1989 de l'Anthologie de la demi vérité intitulée «Deux Québec dans un»! 
Croyant les Canadiens français d'ici beaucoup trop faibles aux plans démographiques, économiques et politiques, le gouvernement choisira vraisemblablement de décréter un traité découlant de l'Approche commune. Force est donc de conclure que nous devrons nous donner les moyens d'aller devant la Cour suprême du Canada afin d'y faire reconnaître nos droits fondamentaux garantis sans discrimination puisqu'en fait et en droit, il nous est tout à fait possible de soutenir une vaste Cause en droit à l'égalité. Au moins, pourrons-nous ainsi sauver ce qui restera du pays. Dans le cadre d'une telle cause, la preuve des effets de la violation de nos droits repose sur une série de constats qui, depuis 1986, sont observés, vérifiés, démontrés et connus. Voici les principaux ${ }^{30}$ :

Touchant nos élus territoriaux : par le résultat de leurs agissements, c'est-à-dire les inégalités qu'ils ont laissé se créer et se perpétuer, nous disposons d'assez d'éléments de preuve pour leur apprendre et leur montrer, qu'ils ont violé le Serment de loyauté au peuple du Québec, la loi de l'Assemblée nationale, la Charte canadienne des droits et libertés, la Charte des droits et libertés de la personne du Québec et le Pacte International Relatif aux Droits Économiques, Sociaux et Culturels ${ }^{31}$. Ils ne se sont pas acquittés adéquatement et prudemment de leur engagement à remplir les devoirs de leur charge et leurs fonctions de député, à savoir :

1. Analyser les lois proposées (par le gouvernement).

30 Tous les points de la démarche juridique, ici énoncés ont été éprouvés dans une foule d'autres procès en matière de droits à l'égalité devant la Cour suprême du Canada.

31 Ce Pacte s'insère dans le cadre de la Déclaration universelle des droits de l'Homme. 
2. Contrôler l'application de la loi par le gouvernement et par l'administration publique, conformément à la Constitution et à la Charte des droits et libertés enchâssée dans la plus haute loi du pays.

3. S'assurer que la communauté qu'ils représentent reçoive, par rapport aux autres communautés, sa juste part des programmes publics ${ }^{32}$, le plus important levier de répartition de la richesse.

Les élus ont laissé le gouvernement agir de manière à ce que soient violées les articles 15, 7 et Premier de la Charte canadienne des droits et libertés et l'article 36 de la Constitution. En l'occurrence, il s'agit de :

- Nos droits garantis à l'égalité sans discrimination;

- Nos droits garantis à pouvoir demeurer dans notre région d'appartenance sans avoir à subir les effets de politiques d'application dont la nature nous contraint à en partir;

- Notre droit à ne faire l'objet d'un traitement différent à moins qu'il soit explicitement justifié par le gouvernement dans le cadre d'une société libre et démocratique;

- Nos droits à l'égalité des chances économiques entre les régions ${ }^{33}$.

32 Les programmes publics constituent la majeure partie des intrants en devises pour toutes les régions. Ils sont donc le principal déterminant de l'emploi, donc de la pauvreté (lorsque des restrictions limitent l'accessibilité à de tels programmes).

33 Dans le cadre de l'Approche commune, chaque député, à titre de représentant territorial, devrait se voir sommé et mis en demeure de veiller à faire son travail en prenant dans le dossier, la place qui lui revient de droit, c'est-àdire toute la place. Muni de sa Constitution, des constats sur les inégalités tel que son devoir et la loi l'exigent - au nom de sa communauté territoriale, 
La politique québécoise de prétendu développement économique régional, au Saguenay-Lac-Saint-Jean et sur la Côte-Nord est le moteur de la violation de nos droits fondamentaux garantis à l'égalité des chances sans discrimination. Les faits observables et vérifiables plaident d'eux-mêmes en notre faveur. Ils nous permettent de démontrer que la violation de nos droits fondamentaux à l'égalité repose sur le motif illicite de discrimination fondé sur la région d'appartenance ou fondé sur la condition sociale, du fait d'appartenir à une région géographiquement, économiquement et socialement exclue et «éloignée » de la grande région de Montréal ${ }^{34}$.

L'action gouvernementale a eu pour effet, depuis au moins 1982, de compromettre gravement l'exercice de notre droit fondamental individuel et collectif à l'égalité sans discrimination, notamment en matières sociale et économique :

- Notre communauté régionale d'appartenance et plusieurs autres ont été, en 1973, étiquetées « régions ressources ». Depuis lors, nous sommes sans cesse pénalisés.

- La Législature du Québec qui regroupe nos députés n'a posé aucun geste pour que l'étiquette «régions ressources» soit

il devrait veiller à ce qu'il ne soit nullement accordé un traitement différentiel aux Innus, du fait que la communauté qu'il représente, vue sous l'angle de son sous-développement, a les mêmes besoins et doit bénéficier des mêmes solutions que celles véhiculées par l'Approche commune. Dès maintenant, il devrait être formellement informé que s'il laisse se conclure l'action gouvernementale envers les Innus seulement, il sera immédiatement dénoncé en justice, pour les mêmes violations précédemment énoncées.

34 La Cour suprême du Canada reconnaît la non-exhaustivité des motifs identifiés dans l'article 15 de la Charte canadienne des droits et libertés. Sous certaines conditions, peuvent être dénoncés des motifs de discrimination illicites analogues à ceux déjà cités dans l'article 15. (1). 
retirée et que soient combattus les effets de la politique de ségrégation territoriale en matière économique et sociale, attachés à ce concept et à son application concrète.

- Par le truchement de la répartition territoriale du financement des programmes publics, il fut maintenu une différence de traitement selon le territoire régional et local d'appartenance des communautés ${ }^{35}$.

- Cette politique différentielle de traitement traduisait une application stéréotypée de présumées ou de supposées caractéristiques personnelles et de groupe.

- La politique québécoise de redistribution de la richesse collective (et des emplois) entre les régions a eu pour effet le maintien, depuis au moins 1982, d'écarts importants du niveau d'emploi entre notre région et la grande région montréalaise. Ces écarts constants et récurrents ont perpétué ou favorisé l'opinion à l'Assemblée nationale, au gouvernement, dans l'administration publique et dans l'opinion publique en général que les citoyens du Saguenay-Lac-Saint-Jean ou les citoyens des autres régions étiquetées « ressources », sont moins capables ou moins dignes d'être reconnus ou être valorisés en tant qu'êtres humains détenteurs des mêmes droits fondamentaux garantis à l'égalité, et en tant que membre égal à tous les autres membres de la société québécoise.

35 En 1973, le gouvernement convenait que le Québec serait désormais divisé en deux entités géographiques distinctes. Le Québec des régions ressources devenant le panier de provision en jeunesse, en ressources financières et naturelles de l'autre partie du Québec, le Québec de base que nous connaissons comme étant la grande région de Montréal et sa zone limitrophe (voir la figure 1). 
- La politique différentielle de traitement en matière économique et sociale fondée sur la région d'appartenance a eu pour effet de nous exclure des possibilités normales d'un sain développement. Il en est différemment pour les citoyens privilégiés de la grande région de Montréal, comme il en sera différemment pour les Innus.

- Notre situation de sous-développement relatif et ses conséquences par comparaison avec la grande région de Montréal, constituent un affront à la dignité humaine essentielle.

- Cet affront est contraire aux droits de l'Homme, aux Chartes des droits et libertés et au Pacte international relatif aux droits économiques, sociaux et culturels.

- Au même titre que la politique d'attribution de leviers créant le développement régional, le traité Québec-Innu ne tient nullement compte de la situation défavorable qui caractérise notre communauté régionale tout comme celle des Canadiens amérindiens visés.

- Compte tenu de la similitude des maux économiques et sociaux découlant du sous-développement économique et social, ce gouvernement ne peut créer, par ce Traité et pour une deuxième fois en trente ans, une différence réelle de traitement entre notre communauté et la communauté autochtone amérindienne.

- Cette politique de traitement différent a pour effet d'imposer à la communauté régionale canadienne française un fardeau ou une privation d'avantages essentiels. Une telle privation est de nature à empêcher qu'il soit permis d'atteindre un développement véritable : celui qui se traduit par la réduction des écarts dans les niveaux d'emplois, par exemple.

- Le traité amérindien aura pour effet de priver la population autochtone non amérindienne d'une partie du territoire, de ses ressources collectives et de la reconnaissance de divers droits 
collectifs fondamentaux. Ces droits nécessaires au sain développement, ce gouvernement les reconnaîtra seulement à la communauté autochtone amérindienne alors que la collectivité autochtone régionale de souche européenne en éprouve le même besoin.

- Enfin, par la signature du traité amérindien, en raison de son contenu et des droits qu'il reconnaît - sans en reconnaitre quelque équivalent que ce soit à notre région qui a subi des effets cumulatifs similaires nés d'une politique discriminatoire - les membres de notre communauté régionale d'appartenance seront amenés une fois de plus à se percevoir comme des membres moins capables, moins méritants et moins dignes d'êtres reconnus ou valorisés en tant qu'être humain ou en tant que membre de la société canadienne ou québécoise.

\section{Prendre action}

$\underline{\text { Retour à la table des matières }}$

En pratique, il est maintenant impératif que nous prenions différentes actions. Celles-ci font appel à notre identité de bâtisseurs de pays qui s'étaient donné des Institutions démocratiques, des droits et qui, résolument pour leur survie, renouent avec la réalité. Ces actions interpellent directement ces Institutions que nous avions mises à notre service - et non l'inverse - et auxquelles nous avions donné un encadrement formé de règles établies et de principes stricts. À ce titre, souvenons-nous que nous avions déterminé nos droits comme individuels, fondamentaux et inaliénables. Nous pouvons donc les retirer en tout temps, des mains de ceux que nous avions élu pour en user dans l'intérêt de notre société inclusive.

Le premier geste consisterait, dans un premier temps, à élire à tous les niveaux de notre société, des représentants territoriaux indépendants de tout parti politique, compétents et «indétournables » de 
leur serment au peuple, de leur rôle et de leurs fonctions. Dotés de ces qualités essentielles, ils seraient sous la surveillance étroite des citoyens qui, par le biais de nouveaux médias - en particulier la presse écrite - auront renoué avec la réalité. Le mandat prioritaire de nos élus territoriaux sera d'obliger, par le recours à la Constitution et à d'autres leviers démocratiques, la remise en fonction permanente des clauses, règles et principes constitutionnels qui créent et garantissent le développement de toutes les collectivités de toutes les régions sans discrimination. Pour accéder au privilège de représentant, tout candidat, pour garantir son engagement profond envers sa communauté, signera un contrat d'honneur par lequel il s'engage à remettre sa démission en cas de manquement à son programme dûment accepté par les citoyens de sa communauté.

La deuxième action, en appui à la première, réquisitionne ceux d'entre nous qui sont capables de témoigner devant la justice de l'atteinte à leur dignité humaine essentielle, par la politique gouvernementale à l'endroit des régions. L'action fait alors appel directement aux plus hautes instances de l'Institution judiciaire. Elle réclame aussi compensation pour les torts et retards dans le développement social et économique causé par l'effet de la politique d'état consistant à maintenir des inégalités depuis au moins les vingt dernières années. Elle réclame enfin que le gouvernement du Canada fasse son travail constitutionnel et par dessus celui de la province de Québec, intervienne avec aplomb et rigueur, tel que la loi fondamentale de ce pays l'y oblige.

La troisième consiste à porter devant les plus hauts tribunaux, toute entente ou tout traité qui découlerait de l'Approche commune telle que libellée actuellement. Le motif repose largement sur le fait que telle que se dessine l'action gouvernementale, une entente signée ou un traité, aurait pour effet de programmer des droits, des certitudes et des leviers économiques et institutionnels seulement à 
la faveur des Innus alors que les autres collectivités des « régions ressources » ont exactement les mêmes besoins pour sortir de leur sous-développement systématique.

Enfin, s'il advenait que le gouvernement, par lui-même ou par l'intermédiaire de "l'aristocratie » qu'il a mise en place dans notre région, s'applique à entraver notre légitime marche vers la reconquête de nos droits fondamentaux réels, les citoyens devront alors exiger par la voie des tribunaux que leur infériorité et leur exclusion collective soient désormais inscrites en bonne et due forme dans la Loi fondamentale du pays. De cette manière, le monde entier sera à même de constater qu'une nouvelle tyrannie est apparue, au grand jour ...

Plus tard, il appartiendra à l'histoire de juger les canadiens français des « régions ressources». Nos descendants découvriront alors si jadis nous étions un peuple qui s'était laissé épuiser socialement, démographiquement et économiquement, non pas pour le profit des colonisateurs venus d'outre mer, mais simplement pour le profit de colonisateurs issus du Pays que nous avions édifié. Mais l'histoire pourrait aussi nous remercier d'avoir eu le courage d'avoir sauvé leurs pays ou d'avoir fondé à partir des "régions ressources » un vrai pays ou chacun trouverait la liberté dans la réalisation de l'égalité par la voie de l'égalisation des chances en matière sociale et économique. 


\section{Conclusion}

\section{Notre devoir de dignité}

$\underline{\text { Retour à la table des matières }}$

\section{Le gazage de la pensée}

En trente ans seulement, les citoyens du «Québec des ressources » ont vu, impuissants, se mettre en place trois orthodoxies, véhiculées par le discours officiel, qui se sont avérées néfastes. À partir de 1982 en particulier, toutes trois contredisaient les valeurs et les droits fondamentaux pourtant clairement garantis par la Constitution du pays.

- La première orthodoxie affirmait la nécessité du développement exclusif de la grande région de Montréal au mépris des droits fondamentaux des individus composant les collectivités des « régions ressources ».

- La deuxième affirme que - dans un Québec dont la politique régionale repose sur l'inégalité des chances et la dissimulation aux citoyens de ses conséquences désastreuses - l'indépendance viendra par enchantement remettre les régions « ressources » sur la voie du développement alors que les dommages déjà encourus sont irréparables.

- La dernière, plus récente, propose ni plus ni moins la primauté en droits des collectivités canadiennes amérindiennes. 
Au cours des dernières années, seule une poignée de citoyens et de trop rares Élus, oeuvrant à l'échelon municipal, ont eu le courage de dénoncer ${ }^{36}$. Aucun acteur politique provincial ou fédéral n'a encore manifesté assez de loyauté envers sa communauté et de liberté dans sa propre tête, pour oser chercher à comprendre et pour s'imposer d'intervenir efficacement. Alors que l'information descriptive sur la réalité était disponible, aucun des gestes nécessaires pour inverser le cours des évènements ne fut jamais posé. La presque totalité de nos élus se sont faits les champions des trois $\mathrm{C}$ du parfait mouton partisan : Converti, Contraignable et Complaisant.

En matière de gazage de notre capacité de penser et de nous exprimer, les destructeurs de régions que nous acceptons comme maîtres, ont pu briller ... par leur arrogance et leur mépris de la démocratie, sans oublier toutefois de s'accorder des émoluments à même les fonds publics. Lorsqu'en 1999 quelques citoyens questionnaient la généralisation de l'élevage industriel du porc programmée par les multinationales de l'agroalimentaire, ils se faisaient d'emblée lancer à la figure qu'ils faisaient un "psychodrame» et qu'ils étaient «contre l'agriculture » (Le Quotidien, 1999). Quand d'autres interrogeaient la nécessité des mini centrales hydroélectriques sur nos plus belles rivières patrimoniales, ils se faisaient traiter «d'artistes transformés en environnementalistes » (L'Étoile du Lac, 2002). Comme s'il s'agissait de péchés mortels, dans une région considérée « ressource ». Lorsque nous questionnons 1'opportunité d'accorder un traitement différentiel aux Canadiens

36 En septembre 2000, pour contrer la désintégration de leur région et la négation de droits fondamentaux par l'Approche commune, La Société du 14 juillet naissait. Elle était composée de Russel Bouchard, Charles Coté, Charles-Julien Gauvin, Richard Harvey, Daniel Larouche et Mario Tremblay, encouragés par quelques centaines de sympathisants. 
amérindiens, nous sommes accusés de «racisme ». Lorsque bientôt nous questionnerons le fait que nous ne sommes pas traités également selon les dispositions de notre Constitution, on trouvera un baveux, un imbu ou un servile pour nous cracher à la figure que nous sommes des «fédéralistes》 des «anti-québécois》 ou des agents à la solde de quelque force partisane obscure ?

Y a-t-il encore moyen de s'exprimer sans se faire écœurer, dans ce pays qui, voilà trente ans, s'est fait inoculer le virus de la vie-dansl'illusion-et-l'irréalité ? Y a-t-il encore moyen de faire notre travail de citoyen sans se faire contrecarrer par un cerbère de l'illusion péquiste? C'était de représentants qui représentent dont nous avions besoin et non de geôliers partisans élus au suffrage! Mais bon dieu, où ont-ils pris leur mandat démocratique pour agir constamment à faire de ceux qui, justement, font appel à la réalité pour sauver ce qui reste du pays, des rejets de la société dont la tête est presque mise à prix ? Faudra-t-il créer une nouvelle taxe ou lever un nouvel impôt pour que les p'tits maitres laissent les citoyens prendre un bain de vérité ?

À travers ce système d'idées toutes faites et de conformisme obligatoire, un constat se dégage: par leurs agissements, nos représentants territoriaux, le gouvernement et sa petite aristocratie partisane incrustée dans toutes les sphères de notre société sont fautifs. Ils n'ont jamais cessé de poser des gestes dont les résultats étaient contraires aux objectifs inscrits dans notre Constitution. Ils ont laissé le gouvernement transgresser, l'une après l'autre, les clauses qui constituent l'âme et les piliers de cette convention collective citoyenne fondamentale.

Par le discours, ils ont masqué le fait que ce sont eux qui sont à la source et qui font partie intégrante de notre problème. Ils ont laissé le gouvernement nous traiter comme si c'était nous-mêmes qui constituions notre propre problème : eux, en p'tits boss et non en 
représentants, ils ont travaillé pour leurs privilèges et non pour leur communauté.

Dans une pièce intitulée "La différence entre les Blancs et nous », le comédien cri, Dan Burnstick, déclamait : "Les Blancs ont le crime organisé; nous, on a des chefs et des conseils. " Ces quelques mots seraient-ils porteurs de vérités profondes sur les faits de ceux qui nous gouvernent? Devrions-nous en conclure que ceux qui sont gouvernés par de vrais chefs avancent tandis que nous, nous faisons du sur place ? Voilà qui convie à réfléchir, vite et ensemble. Voilà qui nous convie démocratiquement à faire, en l'absence de vrais chefs et de vrais hommes d'État, un maître à bord, car ce pays a perdu son bon sens et est en train de foirer de tout son long, régions « ressources » en tête !

\section{Incursion au pays de la réalité}

«En 2002, que constate-t-on par rapport au développement de l'ensemble des régions qui, toutes ensembles, s'appellent encore le Québec? On constate que la réalité mesurable et les bilans exacts ne semblent pas encore être à la base du travail de développement de nos gouvernants. On constate que la situation des régions, loin de s'approcher d'un développement de l'ensemble, se caractérise par des écarts économiques qu'on ne retrouve dans aucune des autres provinces à l'ouest du Québec. On constate que ces écarts ont grugé dans la population jeune de plusieurs régions au point où celles-ci ont pratiquement perdu leur capacité naturelle de reproduction et sont désormais en dépopulation. On constate que, depuis au moins 1986, ces faits sont connus des décideurs du Québec et que le gouvernement n'a pas encore jugé bon d'assumer à cet égard sa responsabilité. Aussi constate-t-on qu'il n'y a eu aucun redressement depuis lors. De plus, je constate que l'exercice bureaucratique auquel on m'a convié en vue du Rendez-vous national des régions qu'on ose appeler ressources était tricoté de manière à éviter de dire "les vrais affaires $\gg$.

On n'a donc pas affaire à un petit problème à faire régler par quelques bons administrateurs. On a affaire à un problème qui 
menace l'avenir du Québec: c'est un problème politique qu'aucune région ne pourra résoudre avec quelques oboles électorales. C'est peut-être le plus grande épreuve que la société québécoise aura jamais eu à traverser au plan de la solidarité. "

Jean Tremblay ${ }^{37}$, novembre 2002

\section{Dignité oblige}

Pour l'heure, il semble qu'il y ait des citoyens qui entretiennent encore quelques fausses croyances. Ils croient que le simple fait de parler d'indépendance nationale et de quelques bouts de route, les libère de leur devoir sacré de « faire de la politique ». Philanthropes, ils croient que leur collectivité est riche et égale en droits, comparée à celle du Grand-Montréal et à celle des Innus. Aussi croient-ils pouvoir se permettre de continuer à faire un immense cadeau à leur gouvernement. En échange de miettes de droits sociaux et économiques enrobées de discours partisans, ils cèdent à leur gouvernement, le droit de continuer à décider quelles collectivités survivront et quelles seront celles qui, comme le Saguenay-Lac-Saint-Jean, sont vouées à disparaître.

Comment pouvons-nous, en même temps, réussir à dénoncer aux autorités tout mauvais traitement infligé à une bête et, simultanément, ne pas trouver nécessaire de dénoncer à l'Institution judiciaire, la violation de nos droits fondamentaux ? Les faits de la réalité et la loi suprême de ce pays, tracent la direction à suivre.

37 Tous les agents locaux qui mènent, sans entraves, cette région vers sa perte, partant de petits politiciens au Lac-Saint-Jean jusqu'à l'équipe éditoriale du journal régional (à l'exclusion de son caricaturiste), s'affairent d'ailleurs à miner patiemment la crédibilité du maire Jean Tremblay, auprès de ses concitoyens. 
Comme la grande collectivité montréalaise et les collectivités innues, le temps est venu, pour nous aussi, d'exiger la remise en marche des conditions de notre développement par la voie constitutionnelle et institutionnelle. Nous en avons le droit et il en va de notre survie. À cette fin, chacun de nous doit exiger pour sa collectivité locale et régionale, l'application intégrale, non négociable et sans compromis, du droit constitutionnel à l'égalité des chances garanties sans discrimination aucune, incluant celles liées à la région d'appartenance ou à la race.

Déjà affaiblis sur le plan démographique, social et économique, nous pourrions aussi choisir de continuer à être traités injustement et illégalement par la même aristocratie raffinée, condescendante, partisane et sans scrupules. Malgré leurs attitudes et leurs paroles charmeuses, ces "mange canayens français » persisteront, par l'application qu'ils font des lois, à refuser de nous reconnaître pour ce que nous voulons et devons être: des êtres humains et des membres égaux dans la société québécoise et canadienne! Maintenant que nous savons que l'égalité n'a rien à voir avec la grandeur et le faste de nos équipements culturels et de nos centres commerciaux, l'heure est venue de poser un geste démocratique de citoyens responsables de leur communauté d'appartenance et souverains face à eux-mêmes. Il s'agit de faire table rase des monuments humains encombrants - qui fondent et maintiennent la politique québécoise d'inégalité des chances économiques - et de nous défendre !

La loi fondamentale reconnait que nous sommes de Droit, des citoyens tous aussi capables et méritant le même intérêt, le même respect et la même considération de la part de quelque gouvernement que ce soit. Si nous n'avons même plus le courage et la détermination de réclamer à nouveau cette reconnaissance de nos droits fondamentaux; si nous n'osons exiger que la loi fondamentale soit appliquée dans la réalité quotidienne et si nous n'osons pas 
agir pacifiquement, démocratiquement mais fermement, nous ne méritons pas d'autre sort que celui de continuer à nous éteindre au cœur d'un pays qui, sans cesse, va en se rétrécissant en droits fondamentaux et en étendue territoriale.

Pour chacun de nous, nos pères avaient négocié et signé un contrat social fondamental. Dans notre Constitution est encore enchâssée une Charte des droits et des libertés garantis sans discrimination. Au prix d'un effort collectif persévérant et constant, elle nous garantit encore la liberté, l'égalité et la justice. Est-il injuste ou gênant d'en user et d'en tirer profit comme il se doit? D'autres le font pour eux-mêmes et s'en trouvent mieux considérés, écoutés et servis par le gouvernement!

Mais ce n'est pas tout. Une garantie constitutionnelle n'est rien si elle ne se traduit pas par des gestes concrets dont les résultats seraient mesurables, par comparaison aux résultats enregistrés ailleurs, par exemple dans la grande région de Montréal. Pour juger des résultats, il faut être prêt à regarder la réalité, telle qu'elle est, indépendamment de nos goûts et de nos désirs. Aussi, devonsnous, individuellement et collectivement, ne plus nous laisser passivement empiffrer de propagande gouvernementale, de propos faciles et infantiles. Nous ne pouvons plus permettre de voir nos régions utilisées comme un simple moyen et de nous voir imposés, dans la société, une fonction inférieure, des désavantages, des stéréotypes et des préjugés politiques et sociaux. En ces temps de récession démocratique, voilà un luxe que nous ne pouvons plus nous permettre.

Dans ce Québec à deux égalités et bientôt à trois, il y a eu atteinte grave et systématique à notre droit à l'égalité sans discrimination, donc à notre dignité humaine essentielle. Pour la Cour suprême du Canada, le qui, le quand, le comment de cette discrimination sont de loin moins importants que les effets ou les résultats sur chacun de nous et sur nos groupes d'appartenance. Contrairement aux princi- 
pes et aux règles inscrites dans la Constitution, dans les Chartes des droits et libertés et dans la Déclaration Universelle des droits de l'Homme, le gouvernement n'a nullement favorisé pour nous, citoyens hors de la zone montréalaise, l'existence d'une société où tous seraient reconnus comme des membres égaux, tous aussi capables et méritant pleinement le même intérêt, le même respect et la même considération.

Il faut faire plus que d'exiger des comptes. Il appartient à chaque citoyen, pour lui et aussi pour son groupe d'appartenance, de veiller à ce que soient dénoncées sans compassion aucune, à l'Institution judiciaire, les violations des droits fondamentaux garantis par les Chartes québécoise, canadienne et Universelle des droits et libertés. Il appartient également à chacun de dénoncer chaque député - refusant son devoir de protection de nos droits fondamentaux - pour le motif de s'être mal acquitté de son devoir envers son serment au peuple québécois, envers la loi sur l'Assemblée nationale et envers les Chartes et la Constitution. Qu'est-ce donc qu'une collectivité, si elle n'est pas la réunion sur un territoire des citoyens s'appliquant à faire et à conserver leur Pays. Labourer la terre et bâtir maison ne suffisent pas.

Il faut poser en citoyen ses jugements, opiner par soi-même, exiger des comptes, prendre les mesures qui s'imposent pour que le Gouvernement, sous l'autorité de l'Assemblée des députés, soit vitement et sans complaisance remplacé en cas de violation du contrat social fondamental. Ici, dans nos régions étiquetées " ressources », pendant 30 longues années, nous avons assisté, béats, à la violation de nos droits fondamentaux par le gouvernement de notre société, tous partis politiques confondus. Ces droits ne nous ont été garantis ni par les Européens, ni par les Asiatiques. Ils nous ont été garantis par nous-mêmes. Est-ce si difficile à comprendre, à accepter et à intégrer dans le plus profond de nos raisons et de nos cœurs! 
Les temps sont venus, je crois.

Nous devons affirmer que nous aussi sommes reconnus par la loi. Cette reconnaissance, nous la jugerons souverainement sur la base des effets, des résultats de son application.

Nous devons affirmer collectivement que notre condition de citoyen occupant la région du Saguenay-Lac-Saint-Jean ou la Côte-Nord est inhérente à notre propre identité et à notre personnalité.

Nous devons affirmer qu'il s'agit là d'un statut inaltérable et non négociable.

Nous devons affirmer, pour nous-mêmes et pour notre collectivité régionale, qu'aucune législature et qu'aucun gouvernement ne disposent de droits et d'intérêts légitimes pour imposer qu'il faille devenir les citoyens transplantés dans le Grand-Montréal pour être objectivement convenablement traités par la loi.

Enfin, nous devons nous affirmer et affirmer clairement cette vérité : ensemble, nous sommes, de fait, des citoyens canadiens français du Saguenay-Lac-Saint-Jean et de la Côte-Nord.

Pour notre survie dans la dignité humaine essentielle, nous voulons sincèrement que notre niveau de développement économique et social soit égal, ni plus ni moins, à celui de nos concitoyens et frères du reste de la région, du Québec et du Canada.

Tant à l'égard de l'Approche commune qu'à l'égard du développement économique, nous devons devant la justice - à titre de collectivité sous-développée au point que nos jeunes aient dû, par dizaines de milliers, quitter leur région d'appartenance - exiger du gouvernement qu'il démontre en quoi il améliore notre sort à nous, citoyens. À la face même de tous les citoyens du Québec, du Canada et à la face même de la Justice, le gouvernement doit s'acquitter du fardeau de démontrer le bien-fondé du fait que nous 
soyons, encore une fois, exclus du grand partage de la terre, des ressources, de la richesse collective, des emplois et du droit à l'égalité des chances.

Voilà la Loi de ce pays. Voilà ce à quoi nous convie le contrat social fondamental!

Mario Tremblay, 21 décembre 2002 


\section{Références bibliographiques}

$\underline{\text { Retour à la table des matières }}$

Axworthy, Loyd, Le développement régional : l'exemple de l'Ouest.

Dans Les années Trudeau, 1990 (p. 259-276).

Bouchard, Lucien, dans Possibles, (hiver 1991).

Bouchard, Russel, L'Approche commune, 2002.

Carr, Edward H. et al, Nation ou fédéralisme, 1946.

Charte de l'Organisation mondiale de la santé (OMS) pour la promotion de la santé. Ottawa, (Charte d'Ottawa), 1976.

Conseil des Affaires Sociales et de la Famille (CASF), Mémoire à la Commission d'études sur l'avenir des municipalités au Québec, 1986.

Côté, Charles et Daniel Larouche, Radiographie d'une mort fine. Dimension sociale de la maladie au Québec : Éditions JCL, 2000.

Côté, Charles, Désintégration des régions. Le sous-développement durable au Québec: Éditions JCL, 1991.

Côté, Charles, L'état constitue-t-il encore un acteur nécessaire au développement de notre région? Dans Le Pays Trahi, 2001 (pp 53-112).

Dion, Léon, Le dualisme constitutionnel Canada-Québec: Boréal (p. 50), 1995.

Dupuis, Renée, La Question indienne au Canada (p. 76-89), 1991.

Elliott Trudeau, Pierre, Des valeurs d'une société juste. Dans Les années Trudeau, 1990, (p 380-407).

Elliott Trudeau, Pierre, L'essentiel de sa pensée politique, 1998.

Flanagan, T., Premières Nations? Seconds regards: Septentrion, 2002.

Gill, Daniel, Journal La Presse, (novembre 2002). 
Hébert, Jacques, Le législateur au service de la liberté. Dans Les années Trudeau, 1990, (p. 149-163).

Higgins, Benjamin, Fernand Martin \& André Rainauld, Les orientations $d u$ développement économique régional dans la province de Québec, 1970.

L'Approche Commune, autrement appelée Entente de principe d'ordre général entre les Premières nations de Mamuitun et de Nutashkuan et le Gouvernement du Québec et le Gouvernement du Canada, 2002.

Leclerc, Yvon ou Rémi Trudel, Deux Québec dans un, 1989.

Lysyk, Kenneth M., Charte canadienne des droits et libertés: Wilson et Lafleur, 1982.

Office de planification et de développement du Québec (OPDQ), Les orientations du développement du Québec, 1973.

Organisation mondiale de la santé. Charte, 1976.

Parizeau, Jacques, Journal La Presse, octobre 2002.

Pilette, Lorraine, La Constitution canadienne : Boréal, 1993.

Tremblay, Jean, Les régions du Québec en crise. Bilan, enjeux et voie de solutions (document publié à l'occasion du Rendez-vous national des régions), novembre 2002.

Union des municipalités du Québec (UMQ), Rapport de la Commission d'enquête sur l'avenir des municipalités, (Commission Parizeau), 1976.

Arrêts de la Cour suprême du Canada

Andrew, 1989

Corbière, 1999

Delgamuukw, 1997

Eldridge, 1987

Godbout, 1997

Doctrine en matière d'interprétation des articles Premier, 6, 7 et 15

de la Charte constitutionnelle et autres jugements.
Irwin Toy, 1989

Law, 1999

Mittchel, 2001

Slaight, 1989

Vriend, 1998 


\section{Lexique}

$\underline{\text { Retour à la table des matières }}$

Autodétermination: Libre choix du statut politique d'un pays par ses habitants.

Charte: Loi fondamentale.

Citoyen : Celui qui est habileté à jouir sur son territoire du droit de cité. Le droit de cité est le droit d'accomplir les actes et de jouir des privilèges réservés aux membres de la cité.

Collectivité : Ensemble de personnes liées par une organisation commune, des intérêts communs, une personnalité morale.

Constitution: Organisation politique d'un État.

Contrôleur: Chargé d'examiner, de vérifier, d'inspecter de limiter.

Dignité : Respect dû à une personne.

Droit : Ce qui est exigible par conformité à une règle précise, formulée (constitution, loi, ...). Ce qui donne une autorité morale considérée comme légitime.

Essentielle: Relatif à la nature intime de quelque chose. Nécessaire, indispensable.

État: Entité politique constitué d'un territoire délimité par des frontières, d'une population et d'un pouvoir institutionnalisé. Personnifie la nation.

Ethnocentrisme: Tendance à vouloir valoriser son groupe social, son pays, sa nationalité. Établir une distinction comme le fait l'Approche commune entre civilisation occupant de façon millénaire un territoire et d'autres civilisations plus récentes, peut constituer de l'ethnocentrisme et même du racisme. 
Hypothèse :

1) Conjecture concernant l'explication ou la possibilité d'un événement.

2) Proposition relative à l'explication de phénomènes naturels admise provisoirement avant d'être soumise au contrôle de l'expérience.

Institution: Organisme visant à maintenir les règles établies en vue de la satisfaction des intérêts collectifs.

Ecoumène : Partie habitée d'un territoire.

Plaidoyer : Discours prononcé devant un tribunal pour défendre une cause. Défense en faveur d'une personne, d'une opinion.

Politique (une): Ensemble des pratiques, faits, institutions et détermination du gouvernement d'un État ou d'une société.

Politique (la): Relatif à l'organisation du Pouvoir dans l'État, à son exercice.

Ségrégation : Mise à l'écart et privation de certains droits subis par des personnes, des groupes à l'intérieur d'une collectivité.

Serment du député de l'Assemblée nationale du Québec : «Je (nom du député), déclare sous serment que je serai loyal envers le peuple du Québec et que j'exercerai mes fonctions de député avec honnêteté et justice dans la respect de la constitution du Québec ».

Stéréotype : Opinion toute faite, cliché (image négative). 


\section{Remerciements}

Werci à Russel Bouchard, l'historien. À travers son œuvre, j'ai 1 saisi mieux encore la dimension du Pays, pourquoi le chérir et pourquoi me porter à sa défense.

Merci au citoyen Bouchard, pour ses encouragements, ses conseils et son aide.

Merci à Madeleine Bouchard pour ses précieuses révisions et ses patientes corrections de texte ainsi qu'à France Gobeil et Julie Gauthier pour leur aide.

Merci à mes amis Charles Coté, Richard Harvey et Daniel Larouche.

Tous, ils perpétuent une valeur sûre qui maintenant au Québec est rarement mise en pratique : plutôt que créer l'illusion pour cacher les causes, «le travail d'un véritable intellectuel consiste à analyser les illusions pour en découvrir les causes ». A. Miller.

Mario Tremblay 


\section{ANNEXE I \\ Extraits pertinents de la \\ Loi constitutionnelle de 1982}

\section{Partie I : Charte Canadienne des droits et Libertés}

Garantie des droits et libertés

1. La Charte canadienne des droits et libertés garantit les droits et libertés qui y sont énoncés. Ils ne peuvent être restreints que par une règle de droit, dans des limites qui soient raisonnables et dont la justification puisse se démontrer dans le cadre d'une société libre et démocratique.

\section{Garanties juridiques}

7. Chacun a droit à la vie, à la liberté et à la sécurité de sa personne; il ne peut être porté atteinte à ce droit qu'en conformité avec les principes de justice fondamentale.

\section{Droits à l'égalité}

15. (1) La loi ne fait acception de personne et s'applique également à tous, et tous ont droit à la même protection et au même bénéfice de la loi, indépendamment de toute discrimination, notamment des discriminations fondées sur la race, l'origine nationale ou ethnique, la couleur, la religion, le sexe, l'âge ou les déficiences mentales ou physiques.

(2) Le paragraphe (1) n'a pas pour effet d'interdire les lois, programmes ou activités destinés à améliorer la situation d'individus ou de groupes défavorisés, notamment du fait de leur race, de leur origine nationale ou ethnique, de leur couleur, de leur religion, 
de leur sexe, de leur âge ou de leur déficiences mentales ou physiques.

\section{Dispositions générales}

25. Le fait que la présente charte garantit certains droits et libertés ne porte pas atteinte aux droits ou libertés - ancestraux, issus de traités ou autres - des peuples autochtones du Canada, notamment :

a) aux droits ou libertés reconnus par la Proclamation royale du 7 octobre 1763;

b) aux droits ou libertés acquis par règlement de revendications territoriales. (Abrogé et remplacé aux termes de la Proclamation de 1983 modifiant la Constitution).

b) aux droits ou libertés existants issus d'accords sur des revendications territoriales ou ceux susceptibles d'être ainsi acquis.

27. Toute interprétation de la présente charte doit concorder avec l'objectif de promouvoir le maintien et la valorisation du patrimoine multiculturel des Canadiens.

\section{Partie II : Droits des Peuples Autochtones du Canada}

35. (1) Les droits existants - ancestraux ou issus de traités - des peuples autochtones du Canada sont reconnus et confirmés.

(2) Dans la présente loi, "peuples autochtones du Canada » s'entend notamment des Indiens, des Inuits et des Métis du Canada.

(3) Il est entendu que sont compris parmi les droits issus de traités, dont il est fait mention au paragraphe (1), les droits existants issus d'accords sur des revendications territoriales ou ceux susceptibles d'être ainsi acquis. 
(4) Indépendamment de toute autre disposition de la présente loi, les droits - ancestraux ou issus de traités - visés au paragraphe (1) sont garantis également aux personnes des deux sexes.

\section{PARTIE III : PÉRÉQUation ET INÉGalitéS RÉGionales}

36. (1) Sous réserve des compétences législatives du Parlement et des législatures et de leur droit de les exercer, le Parlement et les législatures, ainsi que les gouvernements fédéral et provinciaux, s'engagent à :

a) promouvoir l'égalité des chances de tous les Canadiens dans la recherche de leur bien-être;

b) favoriser le développement économique pour réduire l'inégalité des chances;

c) fournir à tous les Canadiens, à un niveau de qualité acceptable, les services publics essentiels.

(2) Le Parlement et le gouvernement du Canada prennent l'engagement de principe de faire des paiements de péréquation propres à donner aux gouvernements provinciaux des revenus suffisants pour les mettre en mesure d'assurer les services publics à un niveau de qualité et de fiscalité sensiblement comparables. 

Composé en Times New Roman corps 12, cet ouvrage a été achevé d'imprimer

à Ville de Saguenay,

en janvier 2003. 
Détrompé, j'ai observé mes représentants élus au Parlement et le gouvernement de ma société. Je ne puis faire autrement qu'être en perte de confiance envers nos institutions démocratiques.

Je vois maintenant ce vers quoi se dirige ma région et ce en quoi elle m'échappe à jamais. Je comprends que nous devons nous libérer de la domination d'un ancien rêve qui, pour ma région, a entraîné déportation, dépossession et désolation.

Je comprends la nécessité vitale de me réapproprier mon statut d'autochtone canadien français du Québec. En posant ce geste souverain, je reprends possession de mes droits, de ma personne, de ma pensée, de ma volonté et de mon avenir.

Muni de mes droits fondamentaux, tels qu'inscrits dans la Constitution canadienne, je redeviens cent fois plus important que l'illusion souverainiste; je redeviens pleinement capable de devenir égal en tout point aux autres québécois et canadiens.

ISBN 2-9807812-0-7 